\title{
Understanding married women's vulnerability to HIV infection in Egypt: An exploratory study
}

Doaa Oraby

Population Council

Nahla G. Abdel-Tawab

Population Council

Follow this and additional works at: https://knowledgecommons.popcouncil.org/departments_sbsr-rh

Part of the Demography, Population, and Ecology Commons, Family, Life Course, and Society Commons, International Public Health Commons, and the Women's Health Commons How does access to this work benefit you? Let us know!

\section{Recommended Citation}

Oraby, Doaa and Nahla G. Abdel-Tawab. 2016. "Understanding married women's vulnerability to HIV infection in Egypt: An exploratory study." Cairo: Population Council. 


\section{UNDERSTANDING MARRIED WOMEN'S} VULNERABILITY TO HIV INFECTION IN EGYPT: AN EXPLORATORY STUDY

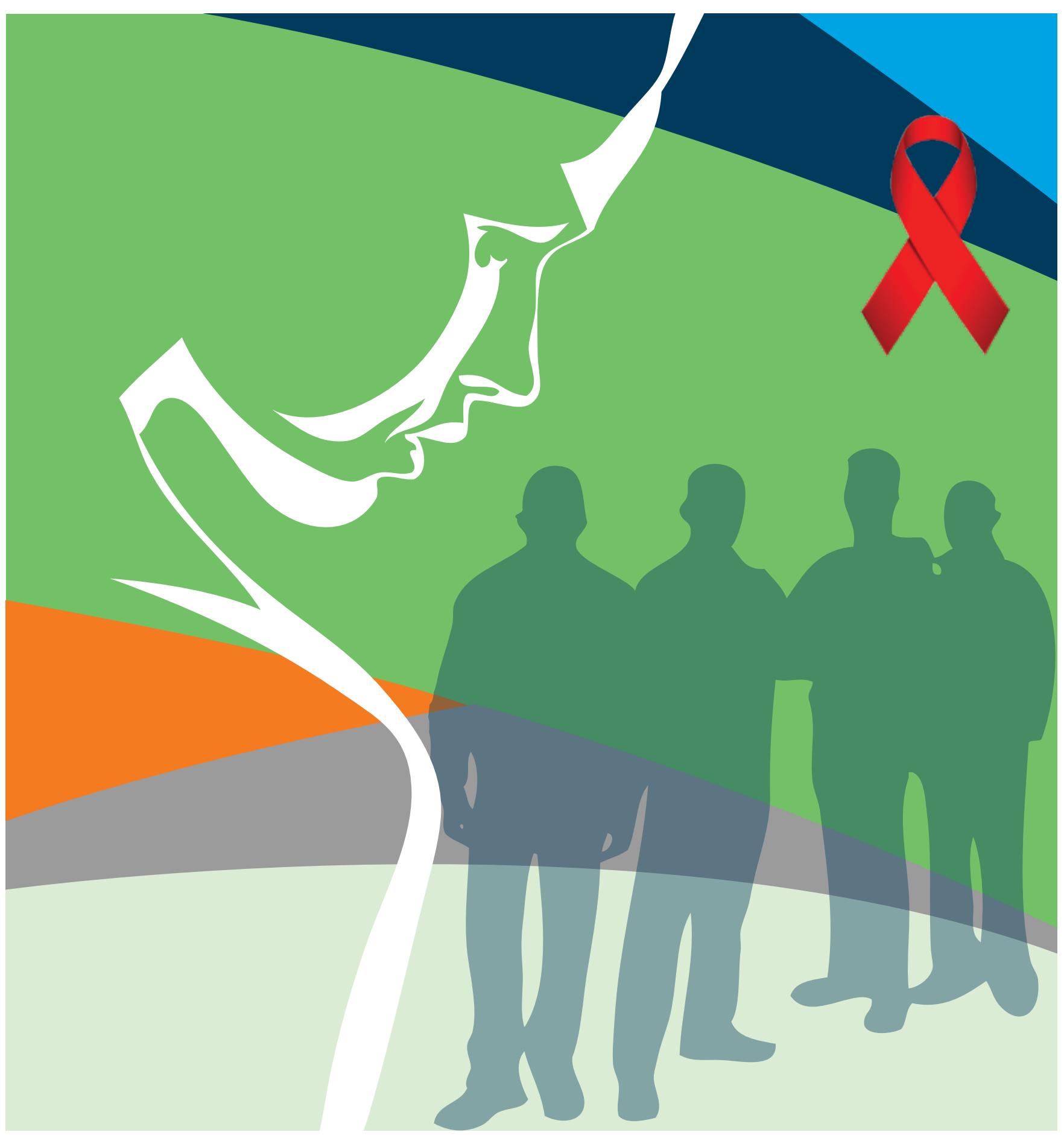




\title{
Understanding Married Women's Vulnerability to HIV Infection in Egypt: An Exploratory Study
}

\author{
Doaa Oraby \\ Nahla Abdel-Tawab
}


Ideas. Evidence. Impact.

The Population Council confronts critical health and development issues-from stopping the spread of HIV to improving reproductive health and ensuring that young people lead full and productive lives. Through biomedical, social science, and public health research in 50 countries, we work with our partners to deliver solutions that lead to more effective policies, programs, and technologies that improve lives around the world. Established in 1952 and headquartered in New York, the Council is a nongovernmental, nonprofit organization governed by an international board of trustees.

Suggested citation: Oraby, Doaa and Nahla Abdel-Tawab. 2016. Understanding Married Women's Vulnerability to HIV Infection in Egypt: An Exploratory Study. Cairo: Population Council.

Population Council- Egypt Office

59 Misr-Helwan Agricultural Road, Maadi

PO Box 168, Maadi

Cairo, Egypt - 11431

Tel. +2022525 5968

Alt Tel. No: (20100)1300-496

Fax: +2022525 5962

E-mail: info.mena@popcouncil.org

Population Council, Inc.

One Dag Hammarskjold Plaza

New York, NY 10017

www.popcouncil.org

Any part of this publication may be photocopied without permission from the Population Council provided that copies are distributed without charge and that full source citation is provided. The Population Council would appreciate receiving a copy of any materials in which the text is used.

(C) 2016 The Population Council, Inc. 


\title{
STUDY TEAM
}

\section{Population Council:}
Dr. Nahla Abdel-Tawab
Country Director
Dr. Doaa Oraby
Reproductive Health Program Officer
Mr. Tarek Alam El-Din
Legal and Implementation Officer
Ms. Gihan Hosny
Program Administration Officer

\section{Consultants:}

$\begin{array}{ll}\text { Ms. Elham Fateem } & \text { Development and Capacity Building Expert } \\ \text { Ms. Sarah Ghattas } & \text { Global Health Consultant } \\ \text { Ms. Leila Sheira } & \text { Fellow, Bixby Center for Global and Reproductive Health, UC Berkeley }\end{array}$

\section{Advisory Group (arranged in alphabetical order):}

\author{
Mr. Sherif El-Kamhawy Program Officer FHI 360 \\ Dr. Ehab El Kharrat Freedom Program Director \\ Sheikh Sayed El Sabahy Muslim religious leader \\ Dr. Fatouh El Shazly Professor of Law, Alexandria University \\ Dr. Walid Kamal National AIDS Program Manager \\ Dr. Sany Kozman HIV expert \\ Ms. Seham Mounir Friends NGO \\ Dr. Sulafa Moustafa Caritas Alexandria \\ Rev. Boulus Serour Christian religious leader \\ Dr. Sherine Shawky Professor of Public Health, American University in Cairo
}





\section{TABLE OF CONTENTS}

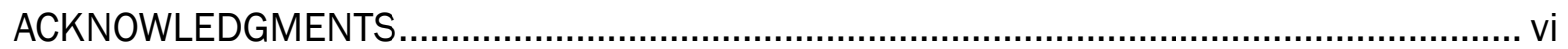

ABBREVIATIONS AND ACRONYMS......................................................................... vii

EXECUTIVE SUMMARY .................................................................................... viii

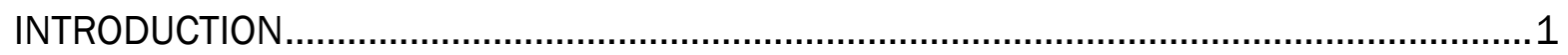

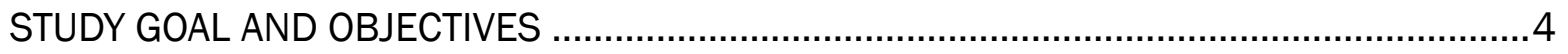

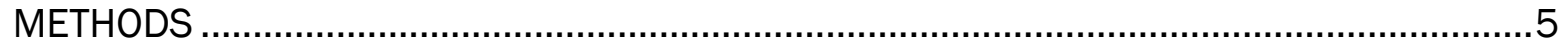

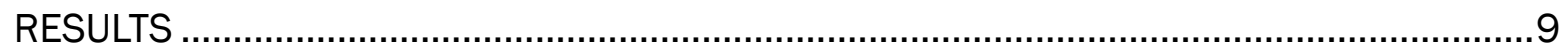

Socio-cultural, economic, programmatic, and legal factors..................................... 9

Married women's persepectives on their vulnerability to HIV..................................... 14

Husbands' behaviors that contribute to women's vulnerability to HIV........................16

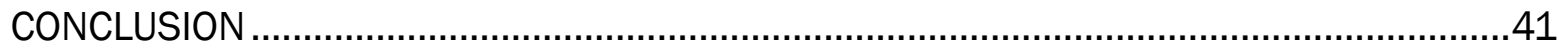

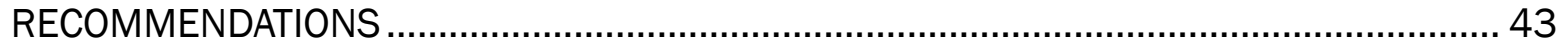

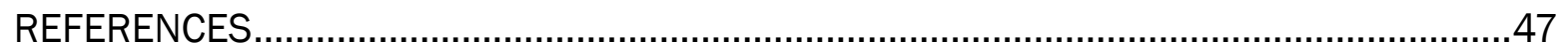




\section{ACKNOWLEDGMENTS}

The study team is grateful to the Ford Foundation for providing financial support for this study. We are also grateful to all the individuals and organizations that made this study possible. We wish to thank Dr. Walid Kamal, National AIDS Program Manager and members of the Advisory Group for their supportive guidance throughout implementation of the study. Our deep appreciation goes to the collaborating NGOs for their assistance in recruiting study participants: NAHR, Caritas in Alexandria, Freedom in Cairo, Friends in Minia, Support for Development in Luxor, and Ma'an in Giza.

Finally, we extend our heartfelt thanks to the men and women who participated in this study and shared deeply personal information about their marital relations and sexual behavior. It is our hope that this study will raise awareness of increased HIV vulnerability of women in Egypt and will lead to policies and programs to protect women, men and children against HIV infection. 


\section{ABBREVIATIONS AND ACRONYMS}

\begin{tabular}{|c|c|}
\hline AIDS & Acquired Immunodeficiency Syndrome \\
\hline BBSS & Bio- Behavioral Surveillance Survey \\
\hline EDHS & Egypt Demographic and Health Survey \\
\hline FGDs & Focus Group Discussions \\
\hline FSW & Female Sex Worker \\
\hline HIV & Human Immunodeficiency Virus \\
\hline IDIs & In-depth interviews \\
\hline IPV & Intimate Partner Violence \\
\hline IRB & Institutional Review Board \\
\hline $\mathrm{MCH}$ & Maternal and Child Health \\
\hline MSM & Men Who Have Sex with Men \\
\hline MENA & Middle East and North Africa \\
\hline MOHP & Ministry of Health and Population \\
\hline NAP & National AIDS Program \\
\hline NGO & Nongovernmental Organization \\
\hline PLHIV & People Living with HIV \\
\hline PWID & People Who Inject Drugs \\
\hline STI & Sexually Transmitted Infection \\
\hline SRH & Sexual and Reproductive Health \\
\hline SYPE & Survey of Young People in Egypt \\
\hline VCT & Voluntary Counseling and Testing \\
\hline WHO & World Health Organization \\
\hline WLHIV & Women Living with HIV \\
\hline
\end{tabular}




\section{EXECUTIVE SUMMARY}

Egypt has a low prevalence of HIV (<0.01 among the general population) with higher prevalence rates among men who have sex with men and people who inject drugs (5.7-5.9\% and 6.5$6.8 \%$, respectively). Although there are no national statistics that document the rising prevalence among women in Egypt, anecdotal findings by service providers in voluntary counseling and testing centers suggest an increase in the number of women infected with HIV. The 2010 BioBehavioral Surveillance Survey noted that approximately one-fifth of men who have sex with men (MSM) and one-half of male people who inject drugs (PWID) were ever married to female partners. In many cases, women may not be aware of the husbands' risky behavior and hence are not themselves aware they are at risk for HIV. The current study focused on examining the behavioral, sociocultural, economic, programmatic, and legal factors that aggravate Egyptian women's vulnerabilities to HIV/AIDS. The results of this study can lead to more gender-sensitive policies and programs.

The study used the following methodology: 1) literature review and critical appraisal of relevant existing national laws and policies related to HIV and sexual and reproductive health (SRH); 2) in-depth interviews with 20 of each of the following groups: MSM, PWID, internal migrant workers, and external migrant workers, to assess the vulnerabilities faced by their wives from their perspective; 3) in-depth interviews with 20 women married to migrant workers; 4) indepth interviews with 20 women living with HIV (WLHIV); and 5) 12 focus group discussions with married women aged 18-40 years. The study was conducted in governorates with a high prevalence of target populations, namely Cairo, Alexandria, Sharkiya, Fayoum, Minia, Sohag, Luxor, and Red Sea.

The current study revealed that women and men are both vulnerable to HIV infection as a result of several interacting factors: the culture of silence around HIV, taboos around the discussion of sexual matters and limited access to HIV-related information. However, the toll of societal norms, gender inequality, economic dependence on a husband, legal discrimination against women, and faulty understanding of religious teachings affect women disproportionately, rendering them more vulnerable to HIV and more stigmatized in case of infection with HIV, a disease that is often linked to "promiscuity."

Women and men interviewed for the current study had limited knowledge and prevalent misconceptions related to HIV. Men did not perceive themselves or their wives as being at risk for acquiring HIV and had a false sense of security with regard to their risk of contracting HIV, considering it "a disease of foreigners." The women who were the focus of this study, although 
did not engage in risky behaviors themselves, turned out to be vulnerable to HIV for being in a marital relationship with men who practiced high risk behaviors including injecting-drug use and/or having heterosexual or homosexual relations. Furthermore, these husbands had limited HIV-related information, negative attitudes toward condoms, and most of them treated their wives violently. The vulnerability of these women is further exacerbated by inequitable gender norms and economic dependence on their husbands, both of which render women powerless to discuss their husbands' risky behavior if they suspect it. Furthermore, women who tried to protect themselves by refusing to have sex with their husbands or insisting that their husbands use condoms were subjected to both physical and sexual violence from their husbands. Some WLHIV even accept the fact that their husbands, who knew they were HIV-positive and could transmit infection, did not bother to tell them of their status or protect them from HIV.

For low-prevalence settings like Egypt, the focus should be on targeted interventions as they are the most strategic and cost-effective. Hence, efforts should be made to reach out to MSM and PWID and to promote harm-reduction interventions including endorsing safe sexand safe injection and provision of condoms and sterile syringes. Ongoing harm-reduction interventions should be scaled up, both geographically by expanding to more governorates, and programmatically by incorporating activities focusing on husband-wife communication. Interventions should include outreach to wives to raise their HIV awareness and enhance their condom use, self-efficacy, and negotiation skills while nevertheless maintaining the confidentiality of their husbands. Additionally, there should be targeted interventions directed toward internal migrants, specifically those working in tourist attractions, and external migrants, especially those living and working in Western countries. The focus should be on HIV awareness-raising with a special focus on the preventive role of consistent, correct condom use, and creating a cadre of peers that could provide psychosocial support and HIV counseling to those workers.

To function smoothly and effectively in a highly stigmatized setting like Egypt, MSM- and PWIDtargeted activities should be complemented with HIV awareness-raising campaigns among the general population to combat HIV-related stigma and discrimination and negative attitudes linked to condom use. Social campaigns focusing on condoms should be encouraged both at the level of the general population and among key populations. Furthermore, premarital and antenatal care programs should include HIV awareness-raising and provider-initiated counseling and testing after screening of women to identify those at risk for HIV infection. Concurrently, efforts should be made to empower women (e.g. through microloans, vocational training) as well as addressing inequitable gender norms and revisiting legislations and policies that discriminate against women and exacerbate their vulnerability to HIV. 



\section{INTRODUCTION}

Like most countries in the Middle East and North Africa (MENA) region, Egypt has a low prevalence of HIV (0.01 \% among the general population) (Ministry of Economic Development and UNDP 2010) with higher prevalence rates among key populations such as men who have sex with men (MSM) and people who inject drugs (PWID) (FHI/MOHP Egypt 2010). There are about 9,500 persons living with HIV in Egypt (National AIDS Program [NAP] estimates), of whom 2,500-4,900 are women aged 15 and above (NAP 2013) most of whom are unaware of their serostatus. Although there are no national statistics that document the rising prevalence among women in Egypt, reports by service providers in voluntary counseling and testing (VCT) centers suggest an increase in the number of women infected with HIV. Women may be affected by HIV directly through their own high-risk behaviors (e.g., injecting drugs or sex work) and indirectly through sexual partnership with men practicing high-risk behaviors (UNAIDS/MENA 2012).

Women married to men who practice risky behaviors may be at increased risk for HIV infection. The 2010 Bio-Behavioral Surveillance Survey (BBSS) showed relatively high levels of HIV infection among MSM and PWID (5.7-5.9\% and 6.5-6.8\%, respectively). Moreover, the survey noted that approximately one-fifth of MSM and one-half of male PWID were ever married to female partners (FHI/MOHP Egypt 2010). Condom use was generally low among those two groups with only 3\% of PWID reporting condom use with their regular noncommercial female partner, while $12-25 \%$ of MSM reported condom use with their most recent male partner. Use of condom by MSM with their wife/female partner was not investigated, and neither were the reasons for nonuse. However, a study conducted in India revealed that stigma and discrimination associated with homosexuality prevented MSM from disclosing their sexual orientation to their spouses, and that wives of PWID often learned about their husbands' drug use behavior after they were married (Solomon et al. 2010).

In many cases, women may not be aware of the husband's risky behavior and hence do not perceive of themselves as being at risk for HIV. In the MENA region, most women who are infected with HIV reported not engaging in risky behavior of their own, which may suggest that they contracted the infection through unprotected sex with their partners. Additionally, women are often unaware of their serostatus, but are first diagnosed after their sick newborn child turns out to be HIV-positive (Aidaoui, Bouzbid, and Laouar 2008; UNAIDS/MENA 2012, Oraby and Abdel-Tawab 2014). This is consistent with results of research from other low-prevalence countries (e.g., India), where marriage was the primary risk factor for most HIV-positive women (Newman et al. 2000). 
Women married to returning migrant workers may be also at increased risk for HIV infection. Egypt sends more than two million migrant workers to work in the Gulf States. While no research has examined their risk behaviors while away from home or when they come back, there is evidence of HIV infection among Egyptian migrants to the Gulf region (Jenkins and Robalino 2003). In fact, a study conducted by Population Council researchers in India showed male outmigration to be the most important risk factor influencing the spread of HIV infection in rural areas (Saggurti et al. 2012). As men stay away from their families and become detached from the norms of home, they may engage in unprotected sex with sex workers or injecting drug use (UNAIDS/MENA 2012). Low literacy rates and prevalent misconceptions about how HIV/AIDS is transmitted add to the vulnerability of their wives to HIV.

Apart from the above factors which may contribute to women's increased HIV vulnerability, there are overarching social, economic, programmatic and legal factors that may have an impact on the sexual practices of men and women thus increasing women's vulnerability to HIV. Economic stresses, including divorce, family troubles leading to runaway girls, survival with an incarcerated husband, and unemployment may force women to engage in sex work (Razzaghi et al. 2006). Poverty forces young women to marry men who are much older than they are or to practice commercial sex work in order to support themselves and their families. At the same time, poverty and unemployment may prevent men from fulfilling their sexual needs through marriage, and hence they may engage in unprotected sexual relations outside the context of marriage.

Gender inequality, gender-based violence, and social marginalization place women at a relative disadvantage in a sexual relationship and limit their negotiating power and ability to protect themselves against HIV infection (Population Council 2007). Women often submit to sexual demands that may increase their risk of HIV acquisition when faced with a real threat of immediate violence compared to the relatively "hypothetical" threat of HIV (Vivian et al. 2003). Findings from 10 studies in Asia, Africa, and Latin America conducted from 1997 through 2007 showed significant associations between men's support for inequitable gender norms and engagement in risky behaviors such as partner violence and less condom use (Pulerwitz et al. 2010).

Given that HIV infections are relatively uncommon in Egypt and associated with prevalent stigma together with the restrictions around discussion of sexuality, research that examines men and women's risky behaviors (within and outside marriage) and the factors that may contribute to women's vulnerability to HIV has been very limited. The little research that has been done focused on male key populations (MSM and PWID) but did not explore their female partners' vulnerabilities or perceptions of risk; nor did it examine practices, attitudes, and beliefs of other groups of men and women who are potentially at risk of HIV infection (e.g., male migrant workers 
and their wives). Finally, most of the available research has incriminated individual behavior as being responsible for HIV infection but has neglected broader contextual factors which may lead women to engage in risky behavior or to continue in a relationship that enhances their risk of infection. The current study examines the behavioral, sociocultural, economic, programmatic, and legal factors that aggravate married women's vulnerability to HIV. Results of this study could lead to more gender-sensitive policies and programs and contribute to the national goal of "zero new [HIV] infections." 


\section{STUDY GOAL AND OBJECTIVES}

The goal of the study is to shed light on the factors that increase the HIV vulnerability of women in Egypt. The specific objectives of the study are:

1. Identify the HIV-related vulnerabilities-including social, economic, programmatic, and legal- faced by women in Egypt;

2. Understand risk factors faced by four subgroups of women in Egypt, namely women married to MSM, to PWID, or to migrant workers; and women living with HIV;

3. Provide Egyptian policymakers and stakeholders with empirical evidence to support policies and programs that reduce women's (and men's) vulnerability to HIV. 


\section{METHODS}

\section{Data Sources}

To identify the HIV-related vulnerabilities-including social, economic, programmatic, and legalfaced by women in Egypt, the following activities were conducted: 1) literature review and critical appraisal of relevant national policies, program strategy documents, national/major subnational program reports, and policies to ascertain the extent to which they respond to the particular vulnerabilities of women to HIV infection; 2) critical appraisal, with a gender-equity lens, of existing national HIV and SRH-related laws and policies to highlight the degree to which they affect women's access to SRH information and services and ways to protect themselves against HIV; (3) in-depth interviews (IDIs) with married men of the following subgroups: MSM, PWID, internal migrant workers and external migrant workers, women living with HIV (WLHIV) as well as women married to migrant workers whether internal or external; (4) focus group discussions (FGDs) with married women aged 18-40 years. The study instruments were developed in consultation with an advisory group composed of key implementing partners, stakeholders, and members of the study populations. The study protocol and data collection instruments were reviewed and approved by the Population Council's Institutional Review Board (IRB) and a local IRB.

\section{Study sample and recruitment procedures}

The study was conducted in collaboration with NGOs having access to target groups including harm-reduction NGOs focusing on key populations and people living with HIV or communityservice NGOs with links to migrant workers and women married to migrant workers. The study was conducted in governorates where there are relatively large numbers of target populations namely Cairo, Alexandria, Sharkiya, Fayoum, Minia, Sohag, Luxor, and Red Sea.

\section{Men who have sex with men (MSM):}

IDIs were conducted with 20 married MSM who were recruited using a counselor at the NGOs that provide harm-reduction services and have active links with MSM. Inclusion criteria include being married to a woman, above 18 years of age, biologically male, and self-reporting to staff at the NGO having had sex with a man in the past month.

\section{People who inject drugs (PWID):}

IDIs were conducted with 20 married male PWID who were recruited using a counselor at the NGOs that provide harm reduction services and have active links with PWID. Inclusion criteria 
included being above 18 years of age, married and self-reporting to staff at the NGO injecting drugs in the past week.

IDIs with PWID and MSM explored their knowledge of HIV, perception of HIV risk, awareness of possibility of transmission of infection to their sex partners, engagement in risky behaviors, condom use, health-seeking behavior, experience with the healthcare system, and dynamics of the marital relationship including engagement in intimate partner violence (IPV).

\section{External migrants:}

IDIs were conducted with 20 external migrant workers who are currently working outside Egypt (in Arab or Western countries) or who have returned to Egypt from work abroad. They were recruited while they were visiting Egypt on annual leave or when they completed their assignment and settled back in Egypt within the last six months. The sample was recruited with the help of NGOs providing community services in the selected villages.

\section{Internal migrants:}

IDls were conducted with 20 internal migrant workers who have been working outside their governorates for at least one year. The sample was recruited with the help of NGOs providing community services in the selected locations/neighborhoods.

Interviews with external and internal migrant workers explored the same issues that were investigated with MSM and PWID in addition to migrant workers' work experience, and types of stressors they were exposed to while away from home.

\section{Women living with HIV (WLHIV):}

IDIs were conducted with 20 ever-married WLHIV who were recruited using counselor at the NGOs that have active links with WLHIV. IDIs with WLHIV explored behavioral and contextual factors that may have contributed to their infection, wife's and husband's current engagement in risky behaviors, condom use, and husband's support (or lack thereof) in preventing reinfection.

\section{Women married to migrant workers (external and internal):}

IDIs were conducted with 20 women married to migrant workers-whether external or internalthrough the help of NGOs providing community services in the selected villages. Interviews with women married to migrant workers explored the impact of their husbands' absence on their lives, change in dynamics of their relationship, their knowledge of HIV and HIV testing, perception of HIV risk, and attitudes toward condom use. 


\section{Married women (18-40 years):}

Twelve FGDs were conducted with married women with separate FGDs conducted with those aged 18-29 and 30-40 years. Those women were recruited via NGOs providing community services in slum areas or rural areas. FGDs with married women explored their knowledge of HIV, attitudes toward HIV testing and condom use, husband-wife communication, and the prevalent risky behaviors in their community.

\section{Protection of study participants}

Strict measures were adopted to protect participants' privacy and confidentiality. The study was introduced to MSM, PWID, and WLHIV through the counselors of the NGOs that provide services to the above groups. The interviewer did not have direct contact with them until after they had given provisional approval to participate in the study. For the interviews with migrant workers and women married to migrant workers, data collectors were recruited from outside the study governorates and interviewed men and women were not related to each other. All IDIs took place in a private setting within the NGO or another location of the participant's choice. During FGDs, sensitive topics including engagement in risky behaviors or intimate partner violence were discussed while referring to a third party so that participants would not feel uncomfortable or stigmatized. Informed consent was sought from participants before conducting IDIs or FGDs.

\section{Challenges}

The initial study design was composed of two phases: a qualitative and quantitative phase. The qualitative phase was to include interviews with MSM, PWID, WLHIV and migrant workers while Phase II was to involve surveys of external migrants and women married to external migrants. However, the methodology of Phase II was changed based on recommendations of the local Advisory Group who advised against conducting a quantitative survey of migrant workers and women married to migrant workers due to sensitivity of the topic and the anticipated difficulty of securing clearances. Instead, the group recommended soliciting general views of women on their vulnerability to HIV as well as more focused interviews with women married to migrant workers for a better understanding of their personal experiences.

Moreover, accessing the MSM population for the purpose of this study was more difficult than anticipated. Negative media publicity against some NGOs that provide harm-reduction services to key populations during the data collection period led some NGOs to suspend their operations for fear of legal persecution. Also, there were some delays in completion of field activities due to difficulties in accessing external migrant workers who are mostly available during the months of July and August when they return for annual leave. 



\section{RESULTS}

The results of the study are divided into two sections; 1 ) vulnerabilities of women in general, including socio-cultural, economic, programmatic, and legal factors that increase their vulnerability; and 2) vulnerabilities of specific subgroups of women, i.e., women married to PWID, MSM, migrant workers (external and internal), and WLHIV.

\section{Socio-cultural, economic, programmatic, and legal factors}

Based on results of the literature and legal review, four categories of factors that increase Egyptian women's vulnerability to HIV have been identified: socio-cultural, economic, programmatic, and legal.

\section{Socio-cultural vulnerabilities}

\section{Cultural practices:}

Cultural practices such as early marriage and IPV increase women's vulnerability to HIV. Although age of marriage has increased in Egypt and despite the presence of a law that regulates age of marriage, ${ }^{1}$ the 2014 Survey of Young People in Egypt (SYPE) revealed that $21.1 \%$ of married female youth aged 25-29 had been married before age 18. Moreover, the survey revealed regional disparities; among married female youth aged 25-29, with those residing in rural Upper Egypt three times more likely to be married before age 18, compared to those residing in the Urban Governorates and urban Lower Egypt (33.3\% versus 10\%, respectively) (Sieverding and Ragab 2015).

Research suggests that early marriage is associated with elevated risk of IPV and sexually transmitted infections, including HIV, especially when those girls are married to men who are more sexually experienced than themselves (Bruce 2003). Even more vulnerable are girls/ women who are involved in "summer marriages" to wealthy men from the Gulf States. These marriages mostly last a few days to a few weeks and are terminated by the husband's return to his home country.

$\overline{1 \text { Child Law no. } 126}$ for the year 2008 forbids documenting of a marriage contract for those who are under 18 calendar years. 


\section{Socio-cultural taboos around discussion of sexuality:}

The culture of silence surrounding $\mathrm{SRH}$ is pervasive and serves as a formidable barrier against HIV prevention. Conservative cultures value ignorance about $\mathrm{SRH}$, as a feature of femininity and chastity. Additionally, the limited mobility of women compared to men hinders their ability to acquire HIV-related knowledge. The 2014 Egypt Demographic and Health Survey (EDHS) showed that among married women aged 15-49 years, HIVrelated knowledge was very low with only 3.2\% having comprehensive knowledge ${ }^{2}$ about AIDS (MOHP et al. 2015).

\section{Violence against women:}

A recent World Health Organization (WHO) report found that "women are 55\% more likely to be HIV-positive if they have experienced intimate partner violence" (WHO 2013). This link has been repeatedly established in some countries of sub-Saharan Africa, as well as India (WHO 2013, WHO 2012, Silverman et al. 2008). According to the 2014 EDHS, over one-fourth of women (25.2\%) were ever subjected to any form of physical violence and (4.1\%) were subjected to any form of sexual violence (MOHP et al. 2015). Women are often hesitant to seek outside help due to the stigma associated with discussing personal matters outside of the home, as well as a belief that their situation was God's will (Khattab et al. 2007). Although teachings of Islam urge husbands to treat their wives kindly and to be gentle while having sex with them, there is a popular belief that religious teachings give husbands the right to beat their wives and force them to have sex against their will.

\section{Stigma around divorce, HIV, and high-risk behaviors:}

Along with intimate partner violence, stigma related to displaying personal matters plays a large role in exacerbating women's vulnerability to HIV. In case studies of WLHIV in Egypt, several of them reported that they were suspicious of their husbands' behavior, yet they did not ask for a divorce in order not to appear to be "at fault." Even following their HIV diagnosis, many women were hesitant to seek medical care or confide in friends and family for fear of the stigma of being blamed for the virus (Khattab et al. 2007, Khattab and El-Geneidy 2014).

Moreover, women whose husbands are involved in high-risk behaviors (extramarital sex, homosexuality, or injecting drug use) are hesitant to seek support from their community for fear of stigmatization. Case studies of WLHIV in Egypt often cited their belief that their husbands'

2 Comprehensive knowledge means knowing that use of condoms and having just one uninfected faithful partner can reduce the chance of getting the AIDS virus, knowing that a healthy-looking person can have the AIDS virus, and rejecting the two most common misconceptions. 
behavior (and subsequent HIV transmission) was God's will and that they were meant to suffer (Khattab et al. 2010; Khattab and El-Geneidy 2014).

\section{Economic vulnerabilities}

Unemployment rates are high among women in Egypt. The 2014 EDHS revealed that nearly one fifth of women (15.5\%) were engaged in economic activity (MOHP et al. 2015). The relationship between economic status and women's vulnerability to HIV in Egypt has not been sufficiently investigated (Nabhan 2013). However, preliminary qualitative interviews and anecdotal evidence revealed a troubling trend. When women find out about their husbands' risky behaviors, they are not inclined to take action to protect themselves from HIV transmission in order not to disrupt their status quo and lose financial security (Khattab and El-Geneidy 2014). One study reported that an HIV counselor advised a woman whose husband had become HIV positive as a result of having extramarital relation against getting a divorce because the woman had no job and was financially dependent on her husband (Khattab et al 2007).

Furthermore, economic stresses may contribute to the uptake of risky behaviors among males, putting their female partners in a vulnerable position. Unemployment among university graduates was nearly 25\% for men (CAPMAS 2011) and economic woes in Egypt have led many men to work in the Gulf countries in search of an income; Egypt has sent over two million migrant workers to the Gulf. Research suggests that male external migration may be contributing to Egyptian women's vulnerability to HIV transmission. There is a small body of evidence showing that there is an increased risk of HIV transmission among Egyptian migrants in the Gulf (Jenkins and Robalino 2003). Research in other settings has already established a connection between migratory behaviors and HIV transmission in both host and home countries (Michalopoulos, Aifah, and El-Bassal 2016; UNAIDS 2011; Saggurati et al. 2012: Puria and Cleland 2006).

\section{Programmatic vulnerabilities}

Sources of information on HIV modes of transmission or prevention are very limited for women, especially those with little education and/or reduced mobility. Primary care services at Ministry of Health and Population (MOHP) facilities are structured around vertical programs like family planning, maternal and child health care, immunization, and school health among others. None of the above programs provides education and counseling on HIV. Also, routine antenatal care services do not include HIV testing for high-risk women. Although a premarital exam is mandated by law, research suggests that those services are not taken seriously by providers or clients and rarely include SRH counseling let alone counseling on HIV (Abdel-Tawab and Oraby 2015). 
Most HIV prevention work is implemented by the National AIDS program (NAP) of the Ministry of Health and Population. NAP offers awareness-raising activities through seminars and educational campaigns that target the general public, including men, women, young people, and other population groups. The NAP also trains healthcare providers in the clinical care of people living with HIV (PLHIV) and combating stigma and discrimination. Furthermore, the NAP provides voluntary counseling and testing (VCT) services free of charge through VCT centers in most governorates. Also, the NAP is responsible for administration of antiretroviral drugs to eligible HIV cases, prevention of mother-to-child transmission services, as well as referral of PLHIV to curative care at fever hospitals.

Provider-initiated counseling and testing is offered at tuberculosis centers, drug rehabilitation centers, selected maternal and child health centers, and sexually transmitted infections care sites. Testing in the private sector is largely unregulated and there are no known reports on the extent of private testing. NAP requires that HIV testing be confidential and preceded and followed by counseling (Hermez et al. 2010). However, limited knowledge of and access to VCT services, especially among women, may increase their vulnerability to HIV infection. In Egypt, fewer women present for HIV testing and counseling than men; $23.3 \%$ of all VCT clients are females (NAP VCT data 2009). Although people who test positive are advised to inform their sex partners, a survey of PLHIV who had regular follow-up visits with the NAP in Egypt in 2010 indicated that $66 \%$ of the married men in the sample had not informed their wives of their HIV status (Khattab et al. 2010).

People at high risk for contracting HIV such as MSM, PWID and FSW receive "harm reduction" services that are mostly offered through local NGOs. There are approximately 15 harm-reduction centers nationwide. Services delivered at these centers are anonymous and free of charge. They include health education and counseling on safe sex and safe injection, HIV counseling and testing, in addition to distribution of condoms and sterile needles. Harm-reduction centers utilize outreach workers of the same target group and word-of-mouth by their clients to recruit new clients. However, harm reduction programs find it challenging to access wives of key populations as reaching those women would inevitably breach confidentiality regarding their husbands' high-risk behaviors.

Furthermore, the absence of sexuality education increases the HIV vulnerability of women as demonstrated later through IDIs and FGDs that revealed deficient HIV-related information and prevalent misconceptions. Additionally, HIV prevention programs rarely address inequitable gender norms or husband-wife communication. 


\section{Legal vulnerabilities}

Egypt has endorsed and ratified most of the international conventions and agreements that protect human rights. While national laws usually go in tandem with these agreements, there are some loopholes in implementation or interpretation of those laws, prompting discrimination against woman. By Egyptian law, voluntary divorce is the right of men only. According to Article 6 of Law No. 25 of 1929 amended by Law 100 of 1985, the wife may ask for a divorce for predetermined reasons. Seeking divorce can be justified by the occurrence of real or potential harm if the husband is involved in risky behaviors that increase the likelihood of contracting HIV infection and its transmission However, in this case, the wife has to provide evidence of her husband's involvement in these risky behaviors, which is often difficult to prove. Moreover, the process of divorce through the court is further complicated by the lengthy procedures and insistence of some husbands on further prolonging the process to increase their wives' suffering.

Pursuant to Article No. 9 of Law No. 10/1961, the act of prostitution is criminalized for providers of the service (i.e., sex workers or pimps) for up to three years in prison. However, according to this law, clients of prostitutes (usually men) are not subject to punishment. Likewise, Egyptian law discriminates between men and women in adultery crimes. The Penal Code punishes women who commit adultery without any further condition or restriction. Men, however, are only penalized if they commit adultery in the matrimonial home. Such discrimination may indirectly encourage men to seek extramarital relations. This discrimination in favor of men may encourage men to have pre- and/or extramarital relations with sex workers or other women thus exposing themselves and their current or future wives to the risk of HIV.

Egyptian law does not punish a husband for beating his wife unless the beating leads to an injury. However, a woman is entitled to a divorce if she provides "evidence" that her husband is physically abusing her. Given the fact that this violence usually occurs behind closed doors, women may not be able to provide such evidence. On the other hand, women who are admitted to hospital as a result of an injury caused by her husband are often persuaded by attending doctors and police officers not to file against their husband so as not to disrupt their marital relationship.

Article No. 267 of the Egyptian Penal Code $^{3}$ criminalizes sexual intercourse with a woman against her will (without excluding within a marital sexual relationship). However, Egyptian judges, who are predominantly men, are unlikely to consider forced sex within marriage as a form of rape. Also, faulty interpretation of Islamic teachings leads the Egyptian public to believe that women have no right to reject their spouse's request for sexual intercourse.

3 http://www.refworld.org/docid/3f827fc44.html 


\section{Married women's perspectives on their vulnerability to HIV}

This section explores factors that increase HIV vulnerability of married women based on results of 20 IDIs with women married to migrant workers as well as 12 FGDs with married women (18-40 years old). There were no observed differences in results obtained through the IDIs and FGDs; thus they are combined in one section. However, women who were interviewed via IDIs were more daring and were able to express themselves and disclose their feelings and opinions about their relationship with their husbands. Some even stated that their husbands used drugs while others reported being aware of husbands' extramarital affairs.

\section{Knowledge of HIV among married women}

Both IDIs and FGDs revealed a severe lack of information about HIV/AIDS and misconceptions about the disease and how to prevent infection. Some women believed that HIV does not exist in Egypt, only in Western countries where according to them "promiscuity and extramarital affairs are common." Their HIV-related knowledge was acquired from movies, but it was clear that the messages did not reach women or that the information was incorrect because they told different stories citing the same movie (e.g., "Asmaa" movie) ${ }^{4}$. The vast majority of women in IDIs and FGDs described HIV as a contagious, incurable disease transmitted to men by foreigners or sex workers or through sharing utensils with someone infected with HIV. When asked about preventive measures, women stated abstinence and seeking divorce if she suspects her husband's behavior. They also mentioned washing genitals before and after intercourse, isolating the patient, and not eating with him/her. Some mentioned making sure that instruments at the dentist and barber were sterilized. Most women believed that men were more vulnerable than women due to their sexual relations.

\section{Married Women's exposure to risk}

Some women whose husbands were working abroad could sense that their husbands practiced sex with them differently (e.g., different positions, or attitude) and accordingly considered the possibility that their husbands might be having extramarital affairs abroad. One woman stated that her husband practiced anal sex with her and although she knew that it is religiously forbidden, she agreed for fear of ruining her marriage. In FGDs, women revealed their acceptance of extramarital affairs, saying that it is the norm for external migrants to have affairs just as it is for husbands living with their wives.

4 "Asmaa" is a 2011 Egyptian drama film that tells the story of a woman with HIV who struggles to live under the burden of keeping her HIV status secret. It is based on a true story. 
Women pointed out that many wives whose husbands were working abroad were subject to harassment, usually by acquaintances like relatives or neighbors. However, they noted that it is less likely to occur in villages as people know each other, but may happen in the city. They said that a woman, whose husband is abroad must be brave and assertive to discourage harassers, and, as one woman noted, "she should be a man and a woman together." The participants told stories of women who engaged in sexual relations while their husbands were away and were murdered by their families or were divorced and their children were taken away from them.

When asked about IPV, women married to migrants stated that their husbands were able to understand that they were sometimes too tired to engage in sex, but they knew of other women who were beaten by their husbands when they refused to have sex with them.

\section{Condom use among married women}

The majority of women knew that condoms were a method of contraception but had not seen them or knew that they protect against HIV. They heard that some couples used condoms when the wife had her menstrual period. However, they said that men generally refuse to use it because it reduces pleasure and is difficult to use. One woman recalled asking her husband to use one until she gets an IUD inserted, but he told her, "I'm ready to avoid sex with you for a month but will never use the condom." Women knew that condoms are sold at pharmacies but they said it is the man who ought to buy them, as women feel embarrassed to buy condoms.

\section{Married women and HIV testing}

Women did not know where to go for HIV testing, and believed that there were no specialized government places for HIV testing. Some women added that it was better to be tested in private facilities because "government hospitals are not good."

Participating women believed that men would not go for HIV testing, either because they would fear the scandal or because they do not have extramarital sex relations, hence do not perceive of themselves as being at risk. Many women would not go for testing for fear of gossip, but more educated women would go for HIV testing, especially if they were married to men who inject drugs. 


\section{Husbands' behaviors that contribute to women's vulnerability to HIV}

This section focuses on HIV vulnerabilities of specific subgroups of women, i.e., women married to PWID, MSM, migrant workers (external and internal) in addition to WLHIV. It is based on results of IDIs with men who belong to those groups as well as IDIs with WLHIV who describe their experiences with their husbands who had engaged in high-risk behaviors.

\section{Men who inject drugs}

We interviewed 20 male PWID whose ages ranged from 27 to 60 years old, and most of whom had graduated or dropped out of technical secondary education. Most of them are currently working, mainly as taxi drivers. All were married (for 3 to 25 years) and living with their wives, who are mostly predominantly housewives. The wives' education level ranged from receiving no schooling to graduating with a bachelor's degree. The majority of them had children.

\section{Drug use patterns among PWID}

All participants reported having used drugs for at least 10 years. Most of them reported injecting two to five times a day, mainly heroin, in addition to Tramadol and Nalbuphine. Even those who reported having attended drug addiction treatment sessions reported relapses. Some attributed relapse to temptation by the same network of friends and drug users with whom they still maintained contacts. Others attributed relapse to unsatisfactory sexual performance after rehabilitation, despite an increased appetite for sex. Therefore, they resumed injecting drugs to prolong erections and delay ejaculations.

Most participants reported injecting drugs either alone or with a friend and most of them reported using someone else's needle or syringe. They attributed sharing the same needle/syringe with friends to the unavailability of syringes, as many pharmacies restrict their sales, and also to the fact that many pharmacies are closed after midnight.

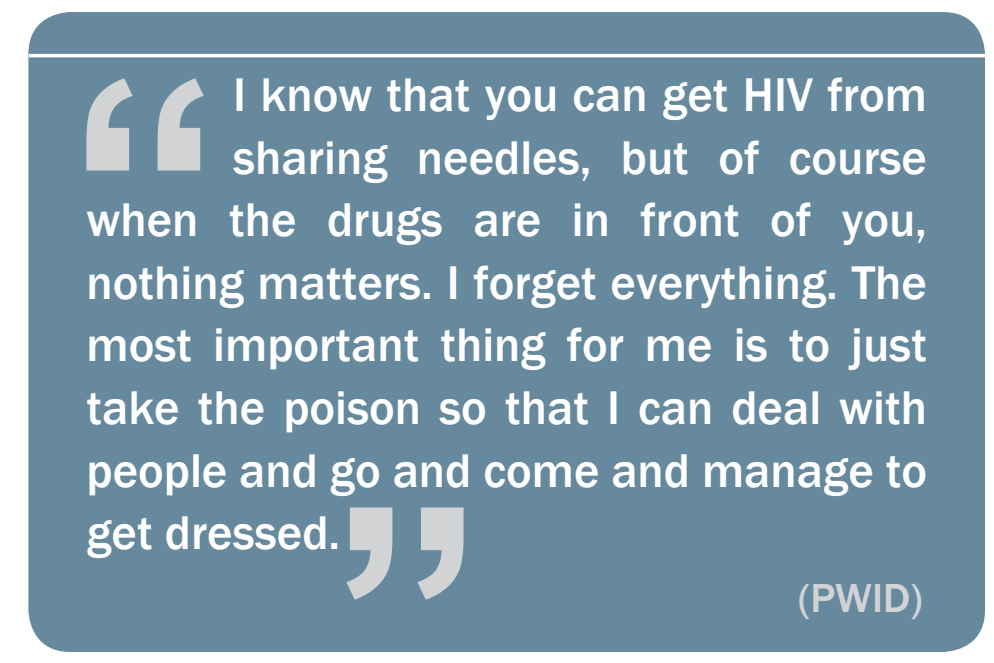


Most admitted that although they are aware of the dangers associated with sharing needles/ syringes, when they are desperately in need of the drug, they are indifferent to protecting themselves. Some participants believed that it sufficed to wash the needle with water and that it was safe to use the same syringe. Some were completely uninformed about the dangers of sharing a needle/syringe.

\section{PWID's marital relationship}

Only two participants reported that their wives were unaware of their drug use. Some managed to hide their drug use from their wives for a few years; they described their wives as initially being too naïve to recognize drug use. Most women found out after getting married. A few women knew about their husbands' drug use before they got married, but their husbands had either quit before marriage and then relapsed, or lied about quitting. Women found out about their husbands' drug use after noticing: needle marks on their arms, finding syringes in the bathroom, observing unusual temper, suspecting missing money or stolen items (like mobiles and valuables) from the house, witnessing them while injecting drugs, and experiencing prolonged erections.

Predictably, after finding out, most wives had heated arguments and fights with their husbands, which were often followed by a period of time spent by the wife at her parents'. Some asked for divorce, but only one got divorced for two years before returning to her husband. All others reunited with their husbands either after false claims about quitting or empty promises to get treated. Others returned for the sake of the children or because they had to accept the situation and move on. However, PWID reported that their marriages were still suffering from continual fights with periods of separation. The wives of those who attempted treatment were initially supportive of their husbands, but fights She got upset and went to her father's house. Her brothers spoke to me about my drug use. I told them 'this is my life and [you] don't give me anything'... she came back. This is how it is.

(PWID) resumed as the husband relapsed.

Most men felt ashamed and guilty for continually disappointing their wives because of their drug use, inability to provide for their families, and reduced sexual desire or poor performance when not under the influence of drugs. They expressed their gratitude to their wives for tolerating their behaviors and continued support during treatment. One man kept repeating how much he hated the way he had become and is hopeful that he will go back to being the good man he once was. 
On the other hand, some men felt their wives had no right to interfere with their addiction. One man said that as long as he is providing for his wife, she has nothing against him. However, they all showed signs of remorse in varying degrees.

\section{Sexual relations of PWID}

There is no better woman than her, and I abused her.... I don't deserve her. I don't deserve her. I don't deserve her. She is a good woman. I swear to God, she has tolerated all, and I humiliated her a lot.

(PWID)

Generally, participants reported diminished sexual desire as a result of their drug use. Some noted that the high they get from heroin is better than that of sex thus sex is often not on their minds at all. Most importantly, heroin addiction greatly affects their sexual performance. If they are not under the influence they experience erectile dysfunction or premature ejaculation and most of them stated that they could not perform at all. Thus, most of them take sexual enhancement drugs and only have sex when under their influence. After injecting, they have prolonged erections and delayed ejaculations that could last for more than an hour. This unusual behavior is very noticeable by their wives and affects their relationships negatively.

With the exception of one, all of the PWID participants had sex with women other than their wives; some with sex workers while others had one or more stable partners. Reasons given for having sex with women other than their wives included: it is a natural and common thing for a man to want more than one woman; other women can perform specific sexual acts that their wives refuse to do; it is necessary when their wives are often fighting with them or when they live separately; some women offer them sex for drugs. Most wives are unaware of those affairs, few are aware of the affairs but have no power or say in it and have learned to accept it, and others suspect it or pretend that they are unaware of it.

When asked if they have ever forced their wives or engaged in violence during intercourse some PWID said that their wives had never denied them sex. Others admitted to hitting their wives for not wanting to continue during intercourse. One participant broke his wife's nose, while another pushed his wife into a piece of furniture, injuring her head, and then

No such thing as her denying me [sex]. If she denies me, I will beat her up....Yes; I hit her before and also did what I wanted to do.

(PWID) continued intercourse. 
On the other hand, many said that they would never hit their wives, but some admitted to using force with women they have affairs with. One man mentioned that he and two of his friends raped a sex worker who had denied them sex.

\section{Condom use among PWID}

Despite having affairs with multiple women and sharing needles and syringes, most participants reported not using a condom with their wives or with other women. Some of them used a condom only when they had sex during a woman's menstrual period. One man reported that he used condoms with a sex worker in Europe because she obliged him to. Most men expressed dissatisfaction with condoms because they felt that they could not reach the same level of sexual satisfaction while using them. Very few men said that they used condoms occasionally, but only with women other than their wives, because they were worried about contracting a sexually transmitted infection.

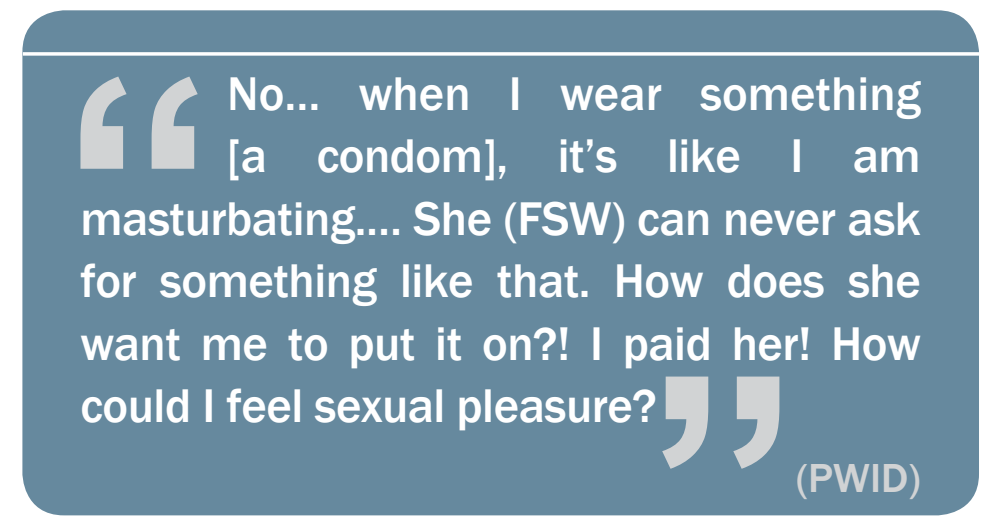

Some said that their wives do not know what a condom is, or would be embarrassed to ask them to use a condom and most said that even if their wives asked, they would refuse.

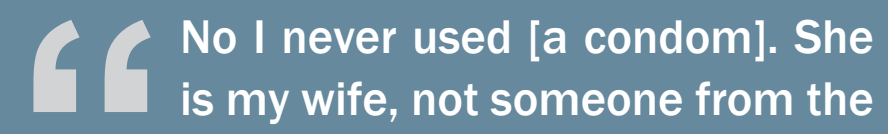

streets.

(PWID)

However, a few seemed genuinely worried about their wives' health and said that they would accept if she requested them to use it. Nevertheless, they would not use them without being requested to do so. Unfortunately, none of the men said that their wives asked them to use condoms.

Only two participants had previously had sex with men; one said that it happened once when he was 14 years old. Others explained that they are sometimes offered drugs in exchange for sexual acts with men, but that they do not agree to it.

\section{PWID and HIV knowledge}

Those participants who had some knowledge about HIV being transmitted through sex and blood reported having heard about it on television (e.g., "Asmaa" movie, advertisement campaign 
against HIV, etc.). Others heard about it through their friends or heard of someone who died from AIDS. However, most of the participants had inaccurate information about HIV. A few men thought that it suffices to ensure that a woman had washed well before they have sex. One man said that he protects himself by urinating, washing up, and spraying cologne on his private parts following intercourse. Many believe that HIV could be transmitted through sharing clothes and eating utensils and by physical contact such as hugging. Another man said that there is no treatment for HIV and that the government shoots down people who have HIV. Some believe that the powder of heroin could contain HIV. It is worth noting that some showed indifference toward learning about HIV, thinking that acquiring any disease is up to God alone, or that it is pointless to gain awareness about HIV, because they are unable to take any protective measures while feeling the urge for drugs.

Despite their risky behavior and having wrong information on HIV, most PWID were aware that HIV could be transmitted through blood, sharing syringes, and having sex with multiple partners. Many were aware that they should protect themselves by using condoms and by not sharing syringes. Many answered yes when asked if wives of PWID were at a higher risk of acquiring HIV, probably because they are aware of their own risky behavior.

\section{PWID and HIV testing}

Only three participants had been tested for HIV, and all three were negative; other participants did not know where to get tested or how much it would cost. Some guessed that they could get tested at any hospital or lab. A few expressed concern about confidentiality of the results and said that they would trust private entities more than public ones. One expressed

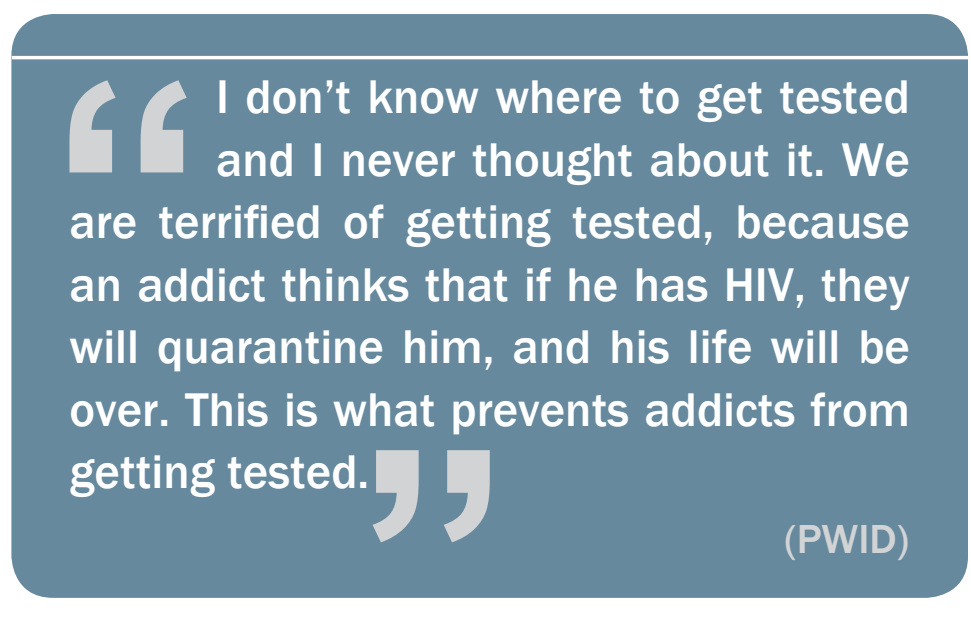
concern about the cost of the test stating that a drug user would rather spend 100 EGP on drugs than an HIV test.

\section{PWID suggestions to protect themselves against HIV}

When asked to make suggestions and recommendations on how to protect PWID from HIV, several participants appealed to the government to eliminate drugs from the streets and offer them treatment. They expressed disappointment about how drugs are widely available and affordable, 
while treatment is too expensive and there are often long waiting periods before getting admitted into a rehab facility. They also attributed drug use to high rates of unemployment, the depression associated with it, and the need to get high and forget one's problems. In terms of effectiveness of TV ads in raising awareness, some thought that they were more useful for women since they spend more time watching soap operas, while others believed that TV ads could be useful for men too. A third group disagreed stating that when under the influence of drugs, men do not waste their time watching television, and if they do, they wouldn't want to watch something about HIV or drugs. When not under the influence, they are too aggravated to watch television. Thus, many believe that the best method is for counselors to talk to them face to face while under the influence and when they are focused. When they are not under the influence, they are unwilling to go to meetings or listen to advice. They also believed that word of mouth from one PWID to another would be effective. Some suggested making condoms and clean syringes free and widely available.

\section{Men who have sex with men}

We interviewed 20 MSM whose ages ranged from 21 to 51 years, and their educational level varied from not having received any education at all to having graduated with a bachelor's degree. They work as salesmen, fishermen, teachers, and various other jobs. Their wives ranged from 18 to 48 years old, most of whom have not received a higher education and all were unemployed except for two. Most men had children.

\section{Marital relationship of MSM}

Overall the MSM interviewed described their marital relationship as normal or good, while a few described their relationship as troubled. They attributed most arguments to disagreements over financial matters or to their lack of sexual desire and their wives' sexual frustration. The men reported different reasons for getting married; a few to settle down and have children, and fewer for love. Several had arranged marriages (mostly to their cousins) despite their lack of interest in getting married, while others chose to get married to cover up any allegations about being homosexual. A few MSM reported that their parents forced them to get married after finding out about their sexual relationships with men.

\section{Sexual relations of MSM with women}

Many MSM expressed no desire to have sex with their wives, because they find themselves more attracted to men. One man was unable to have sex with his wife for the first four days after marriage, and a few months later his wife left him due to sexual frustration. Most men described 
their feelings about having sex with their wives as an obligation; one MSM said that he had not had sex with his wife in several months. Three MSM reported having forced their wives to have sex or having used violence during intercourse due to their wife's refusal to have sex. A few MSM believed that their sexual relationships with men did not affect their relationships with their wives but one MSM attributed his erection problems and premature ejaculation to his sexual relationships with men.

Half of the MSM said that they never had sexual relationships with women other than their wives. In fact they indicated that they do not have any desire to have sex with women. The other half said that they previously had or still have multiple female sexual partners. One reported having as many as 15 female sexual partners, while some reported having had sex with sex workers, and others with acquaintances. Most MSM reported that their sexual relationships with women were before marriage. None of the MSM mentioned using force during intercourse with their

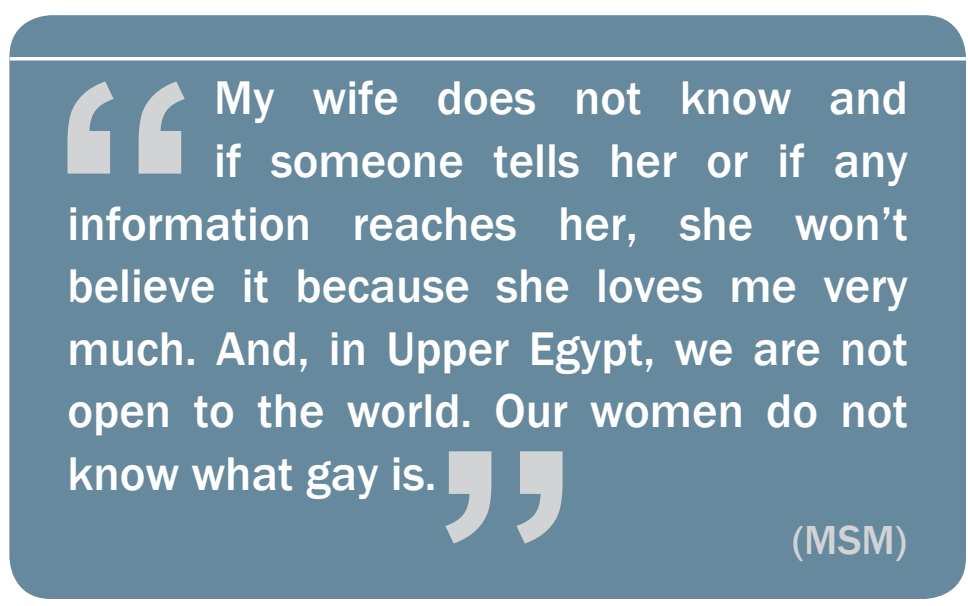
female sexual partners.

All MSM, except for two, stated that their wives were unaware of their sexual relationships with other men or women. They mentioned some precautions that they take so their wives won't get suspicious. For example, one MSM noted that he has a second cell phone line, which he uses to contact his male sexual partners. However, two wives found out about their husbands' sexual relationships with men. One knew when her husband was arrested for engaging in sex with men. Her family asked her to get a divorce, but she refused and continued to be with him. The other, who happened to be his cousin, found out before they got married but they proceeded, in order to dispel neighbors' allegations of him being homosexual. She loved him and believed that he would stop having sex with men once they got married, but he was unable to have sex with her, and she eventually left him.

\section{Sexual relations of MSM with other men}

Most MSM practiced sex with multiple male sexual partners. Seven out of 20 MSM who were interviewed reported that besides practicing sex with men for pleasure, they also practice it for money. Several MSM mentioned that they were often invited to big parties and gatherings where food, alcohol, and drugs were all paid for, and that they sometimes received other gifts. Two MSM reported paying other men to practice sex with them. According to interviewed MSM, 
violence is a natural part of homosexual practices, thus most MSM reported that they do engage in violence during intercourse with other men, but this depends on the mood and preference of their partner. Moreover, some MSM reported having been forced to have sex. One man reported being arrested on homosexuality charges and thus he was detained at an infectious disease hospital where other MSM were detained in the same ward and where he was repeatedly raped by them.

\section{Condom use among MSM}

Most MSM reported that they had never used a condom with their wives. Some said that the condom decreases sexual pleasure, causes infertility, or is unnecessary if one is healthy, others were afraid that using a condom would raise the suspicions of their wives who would think that they were having affairs. A few MSM expressed strong

A No, of course not. I have never used a condom with my wife. It cannot be that I use it with her. Why would I? She is my wife and I am her husband and it is not logical to use a condom.

(MSM) opinions against using a condom with one's own wife, while a few MSM reported using condoms only when their wives had their menstrual period. According to most MSM, the stigma associated with condom use and its links with illicit sex prevent them from using condoms with their wives.

Only two MSM reported using condoms with their wives as a preventive measure. To justify using a condom with his wife without raising her suspicion, one of them told his wife that he was using a condom because he once slept with a foreign woman and because he often feels sick.

When asked about how they would react if their wives requested using a condom, most MSM said that they would refuse, and would have a fight with her about it. Many believed that such a request would indicate that the wife is suspicious of her husband or that she herself is doing something wrong and in either case this would be

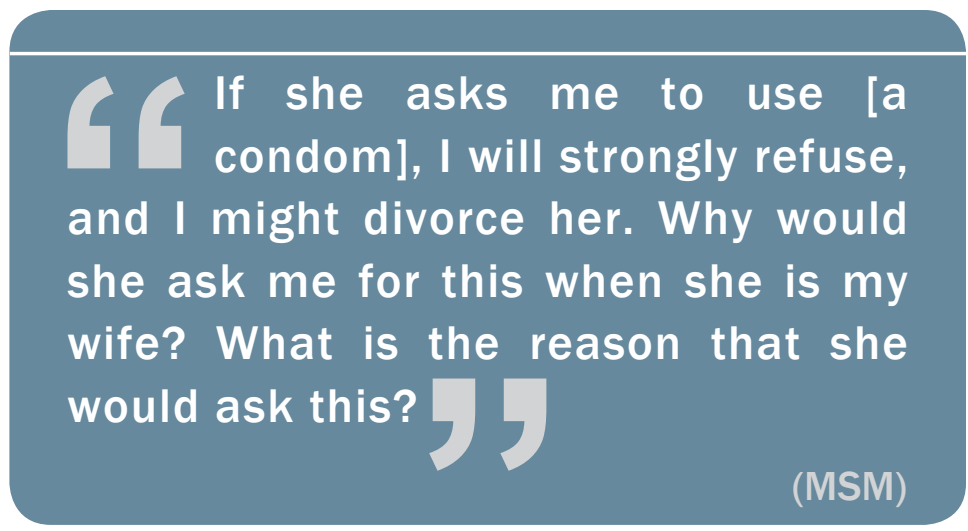
offensive to the husband.

On the other hand, a few MSM said that that they would agree to use condom if their wives requested it or if they (husbands) become HIV-positive. 
Apart from only two MSM who reported consistently using a condom with their male sexual partners, the majority of MSM reported using a condom only with partners whom they were suspicious of. They did not perceive a need to use a condom if their partner was a friend or someone that they usually had sex with. Several MSM reported never having used a condom; most cited a decrease in pleasure as the reason why they dislike condoms. Others did not see the need for condoms because they only had sex with men who have never had sex with men before. Those who had sex with men for money stated that it was up to the paying partner to decide whether or not they should use a condom.

\section{Drug use among MSM}

Although none of the interviewed MSM reported injecting drugs, eight men reported using narcotic pills, such as Tramadol. All other MSM reported using alcohol or hashish or both. Most of those MSM who reported consuming alcohol or drugs indicated that they always had sex under the influence, whether it was with men or women. Some explained that consuming drugs and/or alcohol was common among MSM especially at gatherings and parties to prolong the duration of sexual intercourse.

\section{MSM and HIV knowledge}

Most MSM seemed well informed about the modes of transmission of HIV through sex and sharing syringes. Many of them learned about HIV through meetings held at NGOs. Some of them mentioned hearing about HIV on television or from male sexual partners and friends. However, several of them still had misconceptions about HIV such as that HIV can be transmitted through hugging, sneezing, or sharing clothes or having sex with women during their menstrual period. Almost all MSM agreed that they and their wives were at a high risk of acquiring HIV because the virus was common in the MSM community and because most MSM did not use condoms. All MSM, except

I I am of course at a high risk for HIV because I cannot guarantee the people that I deal with...gay men are at a higher risk than drug addicts because it is spread between the gay community more and it is transmitted quickly among them, and even if we use a condom, it is not completely safe. And, my wife is at a high risk because once I am infected, she will be too.

(MSM)

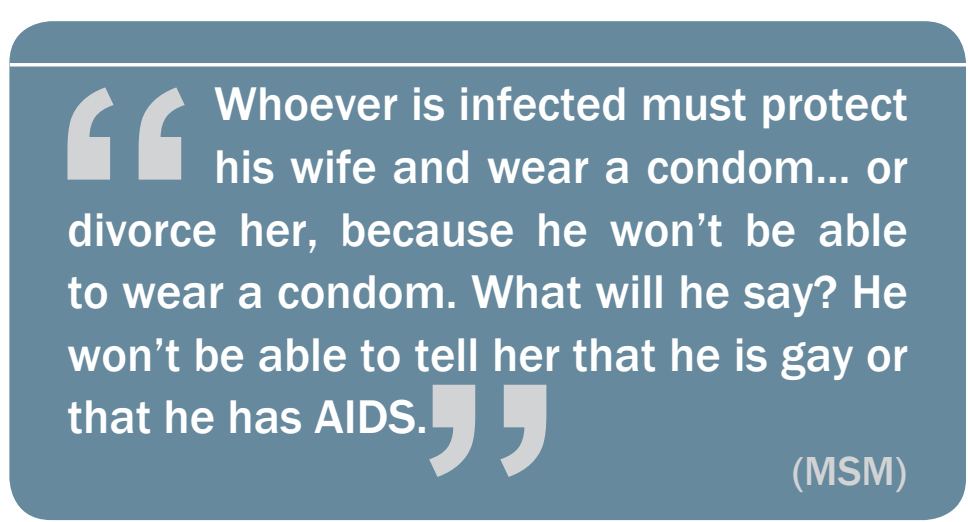


for one, knew where to get tested for HIV and many of them indicated that they previously had been tested for free.

\section{MSM suggestions to protect themselves against HIV}

Almost all MSM mentioned condom use as the best way for MSM to protect themselves against HIV. While many believed that condoms should be used at all times with male partners as well as wives, a few believed that condoms were only necessary when having sex with a stranger or if someone becomes infected with HIV. Another suggestion that they made was to get routinely tested for HIV. Other suggestions included not sharing personal belongings; having only one partner; and choosing safe, healthy partners. Some recommended increasing the number of NGOs that offer HIV testing and awareness.

While a few participants recommended TV as a potentially good venue to reach MSM to raise their awareness, others believed that this topic was too sensitive to be discussed on TV and thus recommended reaching MSM through social media such as Facebook pages and chat groups. Overall, there was general agreement that the best way to raise awareness among MSM would be through meetings and talking to them at their hot spots.

\section{Women living with HIV}

We interviewed 20 WLHIV whose ages ranged from 24 to 58 years and all were ever married. One was divorced and six were widows, five of whom were certain that their husbands died of AIDS. The remaining women were still married to men who were living with HIV. All WLHIV, apart from one, had children; two children were currently living with HIV, while two other children had died of AIDS. These women's educational level, along with that of their husbands, varied from having received no education at all to having graduated with a bachelor's degree. Most of the women were not working for cash, while their husbands had a range of jobs, including driver, chef, and engineer. This section explores behavioral and contextual factors that may have contributed to HIV infection in these women.

\section{WLHIV learning of their status}

Most of the WLHIV learned of their HIV-positive status following their husbands' diagnosis. The husband usually got tested when checking into a rehab facility, or during routine HIV screening for visa applications or to investigate an unexplained fever or illness. Although health workers typically asked HIV-positive men to bring their wives and children for testing, that was not always the case. One woman found out 10 years after her husband died, while another learned about 
her husband's status only when she went to obtain his death certificate. Several women found out about their HIV-positive status following the loss of their babies to AIDS while a few were diagnosed after having unexplained symptoms such as repeated diarrhea and fever. Many of

We didn't know till the day of his death....At the time they didn't tell me what he had or what this disease was....After my husband died, about a year and a half ago, I found myself tired and with a high fever.

(WLHIV) these women reported having to see multiple doctors and complete several blood tests before being properly diagnosed with HIV. It was clear from the testimonials of most of the women that their husbands were aware of their own HIV positive status but chose not to disclose this information to their wives.

The diagnosis affected most relationships negatively, causing arguments between the two spouses. Most women were shocked, felt betrayed, unjustly treated, and emotionally distressed upon learning about their diagnosis. However, as time passed, they had to accept the situation as their destiny. Although several of them considered seeking divorce, they decided not to because they would not be able to remarry or to support themselves or their children after divorce A few were offered a divorce by their husband, but they rejected it in order to take care of their sick husband. One woman returned to her husband after a year and a half of living separately, because she believed that there was no point in avoiding him any longer when they were both infected. Surprisingly, the diagnosis strengthened one relationship; where the husband who was injecting drugs admitted himself to a rehab facility and according to his wife he now cares more about her.

\section{Prior knowledge about HIV}

Although almost all interviewed WLHIV were currently well-informed about HIV, most of them reported having no prior knowledge of HIV. For the most part, women had minimal or false information about HIV which they had obtained from movies such as El Hob fe Taba, Shaweish Nos El Leil,

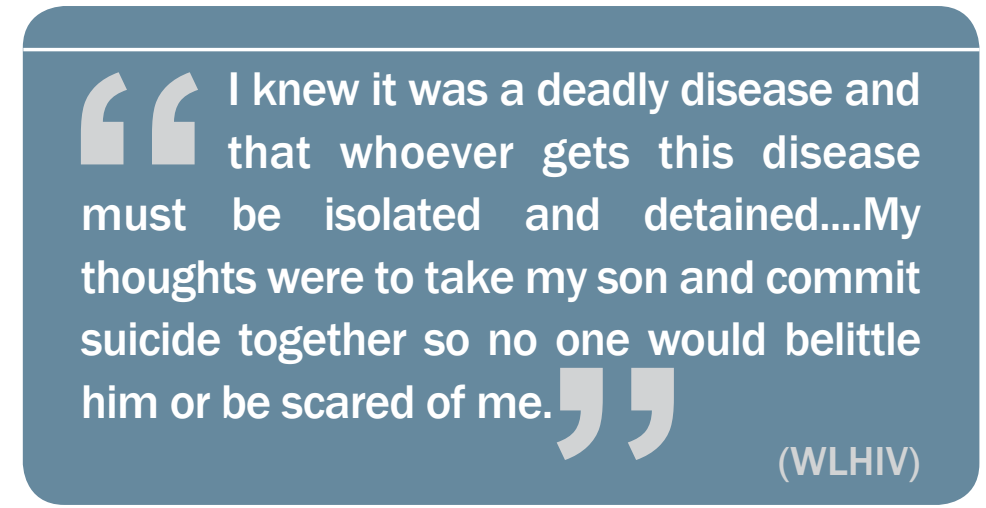
and El Agenda El Hamra. Before their diagnosis they believed HIV was incurable and highly contagious. Thus, one should not touch or share food or clothing with an HIV-positive individual. They were also under the impression that HIV-positive persons were forcefully quarantined or shot dead. 
A few women remembered watching HIV awareness spots on TV. However, one woman argued that those spots further stigmatized PLHIV by only citing sex as a mode of transmission and thus ruining the lives of many people living with HIV.
Say the modes of transmission

are $1,2,3,4$, not one mode and stigmatize us by it, and we can't live. The media destroyed our lives.

(WLHIV)

\section{WLHIV and sexual relationship with husband}

Decreased frequency of sex was common especially in the first few months following diagnosis. Some women attributed this to the emotional trauma which they and their husbands went through following diagnosis, while others noted that the husbands were too sick or were experiencing erectile problems. Moreover, several women reported decreased sexual desire and/or experiencing little or no sexual pleasure with their husbands. They mostly attributed those feelings to fear of HIV progression through intercourse, feelings of hatred, and resentment they were having toward their husbands for causing them this illness. Although many of the women often did not have a desire for sex, most of them succumbed to their husbands' demands, because they believe that it was haram (forbidden by God) to refuse sex with one's husband. On the other hand, four women reported that their husbands forced them to have sex with them.

The majority of women knew where to obtain a condom but almost half the women thought it was embarrassing for a woman to buy a condom at a pharmacy. One woman said that the pharmacist looked down on her when she asked for a condom which made her extremely embarrassed. Despite the fact that most women wanted

Once I found out about AIDS, a big gap separated me and him. At first I hated intimate relationships between me and him. Even when I tried to accept him and feel good toward him, once he came close to me, I hated my whole life in the short time during sex, and I feel this way till now....This has been the case for two and half years since I became aware of my HIV status.

(WLHIV)
We stopped [using condoms], because there was no pleasure. The condom isolates the connection between us and we no longer feel anything. We later dealt naturally. We use it once and two or three times we don't, because we said what else could happen, we have the same disease. 
their husband to use a condom and despite being well informed about its importance, they often practiced sex without a condom, because their husbands refused to use it. Some couples initially used a condom following diagnosis, but then the husband stopped using it because they felt uncomfortable using it, or experienced a decline in sexual pleasure.

Only two women reported consistent condom use. It should be pointed out that during the time when some husbands knew about their HIV-positive status but had not informed their wives, none of them suggested using a condom.

\section{WLHIV and husbands' risky behaviors}

When asked about their husband's use of drugs, the answers were split. Some women were certain that their husbands had never used drugs, while others knew that their husbands had used drugs. Those who knew that the husband was using drugs knew details about the type of drug, the dose, and the location where they bought them. All WLHIV who stated that the husbands used drugs, except for one, confirmed that their husbands had shared syringes with other PWID.

When asked if they were aware of any affairs that their husbands may have had, most women answered yes. Surprisingly, several of the husbands told their wives about their affairs. Some of the men bragged about having those affairs, showing their wives pictures of sex workers and foreign women they had sex with. A few husbands only admitted to having an affair after their wives learned about their HIV status. Two women reported that their husbands had sex with men. Most women felt helpless about those affairs thus did not discuss or argue with their husbands about the matter. Those who did discuss it were reciprocated with verbal and sometimes physical abuse. A few women were uncertain about any affairs while a few others believed that their husband had never had an affair, however neither of these two groups discussed this issue with their husbands. Although several participants suspected that their husbands had had premarital sexual relationships, they never asked them

"I spoke to him a lot about his affairs. His reaction was 'do whatever you please, hit your head on the wall.'... I could have asked him for a divorce if I knew that he could get this disease because of his relations, but there wasn't any awareness at the time and I took things with a simple heart. I started telling myself nothing is wrong with me. What am I missing? I am not ugly. And I realized that no matter what I said, he would increase [his sexual practices] and I didn't try talking to him about this matter [any more]. 
about those relationships. None of the women reported ever participating in any risky behavior such as extramarital sexual relations or injecting drugs.

\section{WLHIV suggestions to protect other women against HIV}

Despite most women reporting that they do not use a condom when having sex with their husband, they cited condom use as the most important recommendation that they would give to any woman, regardless of her husband's HIV status.

They also suggested having prospective husbands tested for HIV and drugs before marriage.
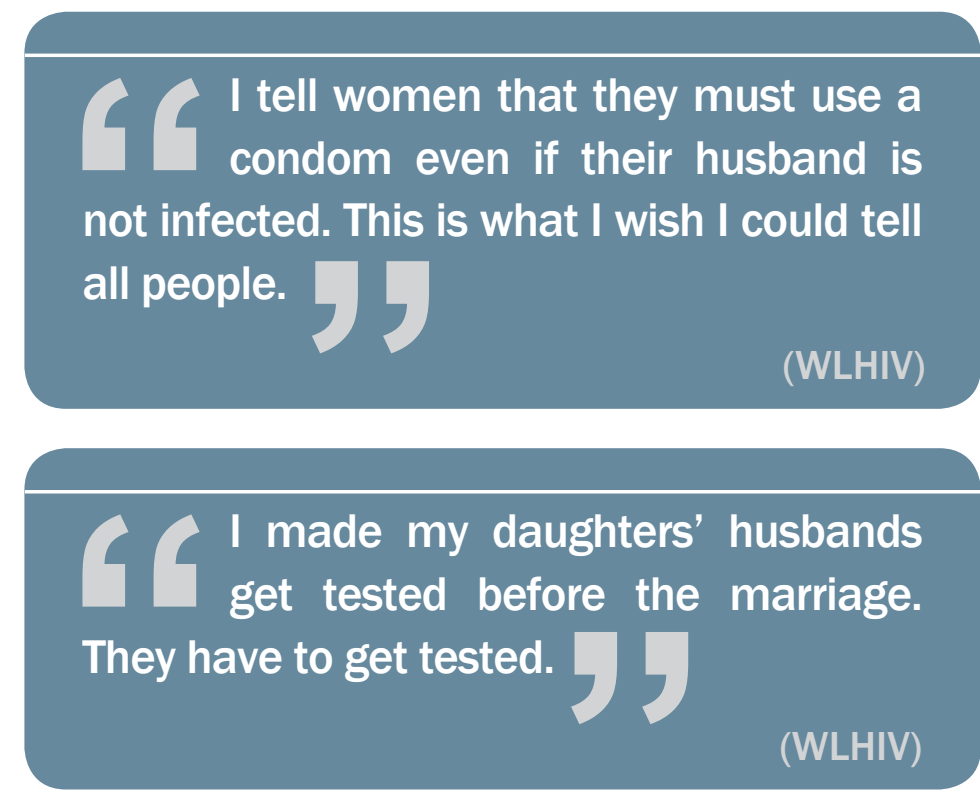

They advised women to find out everything about their fiancé's risky behavior before getting married, and not to take issues such as premarital sex and drug use lightly. Some participants advised wives of injecting drug users or women married to men with multiple sexual partners to get divorced. Other women recommended that couples get routine checkups and HIV testing every six months and to get immediately checked if they experience symptoms such as constant diarrhea and fever. One woman recommended that a nursing mother should interrupt breastfeeding until she gets tested if she suspects her husband is injecting drugs or having affairs.

Most women view media as a powerful venue for changing the stigma against PLHIV. They believe old movies and commercials stigmatize PLHIV and spread false information. However, nowadays the media can decrease this stigma by explaining the different

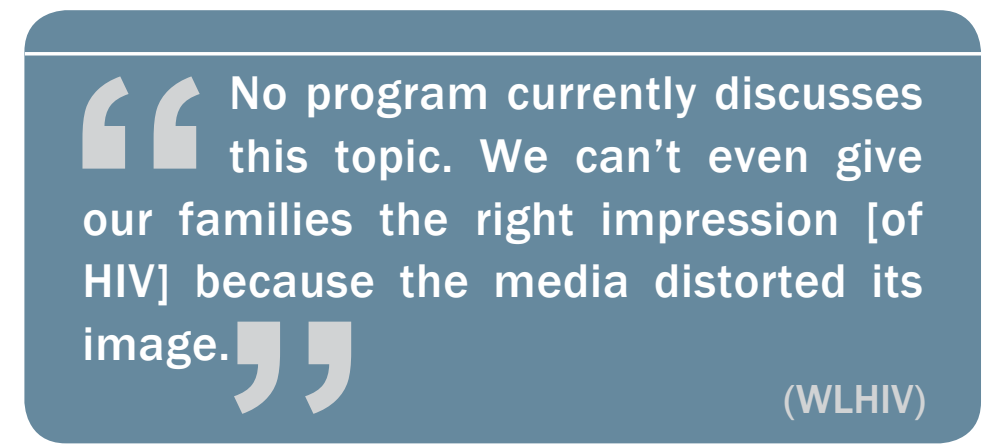
modes of transmission of HIV and by showing that it is safe to share food and clothes with an HIV-positive individual.

Some women specifically recommended condom ads, explaining that there are many commercials for sexual enhancement drugs but none promoting condoms. They believe that it is important to 
present condoms as a modern preventive measure that must be used regardless of illness and risky behavior. However, some women believed that although the media might inform women about HIV, it would not drive women to get tested. Thus, several WLHIV pointed out that it would be useful to raise awareness about HIV through distributing brochures and holding seminars at health facilities (e.g., family planning centers and hospitals) that serve a large number of women. They also suggested that health workers talk privately during routine checkups to women who might be at risk and advise them to get tested, and that counselors visit neighborhoods with a high incidence of drug use to talk to PWID about protection against HIV. One woman advocated for making syringes widely available to reduce the likelihood of needle sharing among PWID.

Several WLHIV recommended including HIV in routine blood tests with hepatitis $B$ and $C$ and making HIV testing more available and accessible outside of Cairo. Finally, some women highlighted the need for covering reproductive health and sexually-transmitted infections in preparatory and high school science classes.

\section{External migrant workers}

We interviewed 20 male external migrant workers aged 27 to 45 years who had been working in Gulf or Western countries for at least two years. All of them either had a bachelor's degree or were graduates of secondary technical schools. Their jobs included working as residential painters, security guards, taxi drivers, accountants, working at clothing factories or restaurants. All of the interviewed men were married for three months to 16 years and the majority had children. Their wives ranged from 21 to 38 years old. Most of the wives had a bachelor's degree or had graduated from a secondary technical school, five wives did not finish high school, and the majority of wives were not working for cash.

\section{Working abroad}

All interviewed migrant workers had been working abroad for more than two years with some working abroad for up to 19 years. Most of the participants were currently working in Gulf countries while three of them were working in Western countries. All men sought to work abroad for better employment opportunities and higher salaries. The experience of working abroad was initially tough for most of the study participants. When they first arrived in the host country, some had to work for two to three years before going on annual leave. Some men reported getting a 2-3-month vacation every two years, while most reported getting a 30-45-day leave once a year. Most migrant workers reported decent living conditions in the host country, where a group of them (three to four) shared an apartment or a villa and split expenses and household chores with housemates. However, a few reported difficult living conditions in which eight workers would 
share a room or 15 workers would share an apartment. Many men lived in apartments that their employers provided. Most men reported getting one day off per week which they would typically spend at home, watching television, playing computer games or card games, attending Friday prayers, hanging out at a café, or calling their

\section{Those who I know are living} abroad only care about money and going home to their kids. If you cannot handle living away from your home and your kids, don't travel.

(External migrant) wives and children.

In terms of health care, migrant workers who had formal jobs reported that they were obliged to sign up for health insurance upon their arrival in the host country. None of the men reported getting routine physical exams. However, they reported going to the hospital when they got sick. Migrant workers who had relatives or fellow villagers said that they often found support including covering their shifts and lending them money during times of sickness, while the rest complained about the lack of any social support abroad. Furthermore, a few men said that their supervisors hardly gave them any sick leave. At times of sickness, they would be pressured to work without receiving any health care. They would only have access to simple painkillers and medications. One man said that he would get fired by his sponsor/ contractor if he got sick for more than two days.

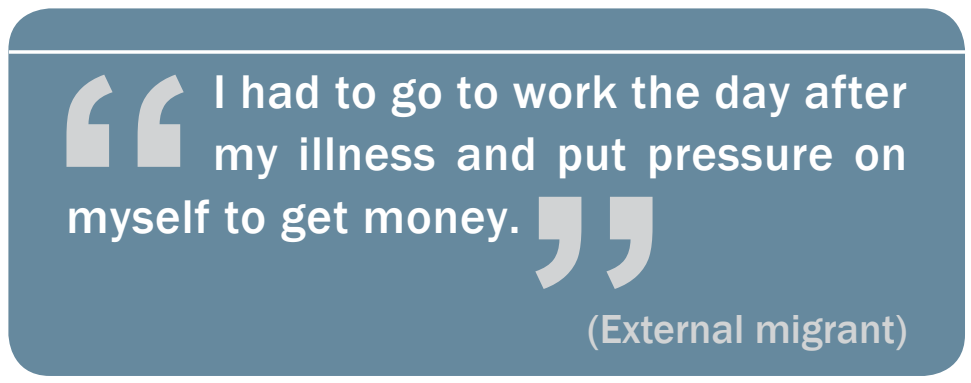

\section{External migrants' marital relationship}

When asked to describe their current relationship with their wives, most men gave positive responses, saying they felt like newlywed couples, and that they loved their wives dearly and were happy when they were together. One man said that he cries at the end of his vacation when he has to leave his wife behind. On the other hand, two men reported that they were having disagreements with their wives, but they avoided fighting in order to spend a good time during their short vacation. Another man said that due to living separately, he was treated really well when on vacation, as if he were a guest. Other men described their relationships as "normal" and said they had become accustomed to living away from their wives. One man added that there was coldness between him and his wife and that the feeling of yearning toward one another only lasts for a week upon his return. 
When asked how they and their wives dealt with separation, some men said that they constantly kept in touch through phone or video calls. Other men said that they got used to living separately. One man said that he no longer thinks about sex. Another said that he and his wife have no strong feelings toward each other. Finally, some men expressed how it is by God's grace that they are able to remain faithful. One man noted that if it were not for daily video calls with his wife, it would have been nearly impossible for him to remain faithful.

External migrant workers who remained faithful to their wives attributed their faithfulness to two main reasons: focusing on their jobs in order to financially support their families and their strong religious beliefs against adultery.

\section{External migrants' sexual relationship with wife}

Most migrant workers did not think that their sexual relationship with their wives had changed over the years. A few men said that sexual coldness increased over the years, "as it typically does between couples" while others believed that it had changed for the better, because living apart made them yearn for one another. None of the men reported practicing new sexual positions with their wives. Furthermore, all men reported that they had never used violence during intercourse. However, one man reported that he scolds his wife when there is tension between them. A third man said that, although he does not use violence with his wife, he sometimes keeps nagging and she eventually responds because his vacation is short.

\section{Extra marirtal relations among external migrants}

None of the interviewed migrant workers reported having extramarital relations. However, most of them knew of external migrants who had sex with acquaintances or sex workers but they did not personally know those men who were unfaithful to their wives. One man confirmed that he intentionally stayed away from other men who could be a bad influence on him. However, they agreed that it was fairly easy for a man to find a sex partner and some even added that in the 
countries where they worked, there are streets and districts known for having sex workers and brothels. A few noted that men who worked as painters or electricians meet cleaning ladies who often make sexual advances to them. Two migrant workers reported that some sponsors/ contractors would supply drugs or sex workers in return for money. One man who worked in a Western country said that most Egyptian men he knew were unfaithful to their wives and that they did not need to pay for sex, because "it was very easy to meet women at nightclubs or bars." One man said that his roommate would have sex while the respondent was in the room, thus he put a curtain in the middle of the room so he would not see him and his partner. He also reported that his roommate once took him to a red light district where there were plenty of sex workers. Several migrant workers mentioned that external migrants who were married tended to be more sexually frustrated than single men who never had sex and hence the former are more likely to seek sexual satisfaction with sex C $[$ Sex] is available there, but it depends on one's faith. My friends would offer me [sex], and women were available there. But, the strength of your faith makes a difference. If you have deep faith and strong belief, nothing like this will affect you. Those who resort to these things are the married men because they are sexually frustrated.

(External migrant) workers.

Only two men reported that they had premarital sexual relations while four external migrants admitted to having extramarital affairs. One man said that he was frequently had sex with sex workers. Another migrant worker who lived in a Western country said that he had lived with one woman for three months, then with another woman for one month, and that he currently lives with a third woman. A third migrant worker, who also lived in a Western country, said that he still had affairs but decreased the number of sexual partners after marriage. The fourth said that he cheated on his wife only once in the past.

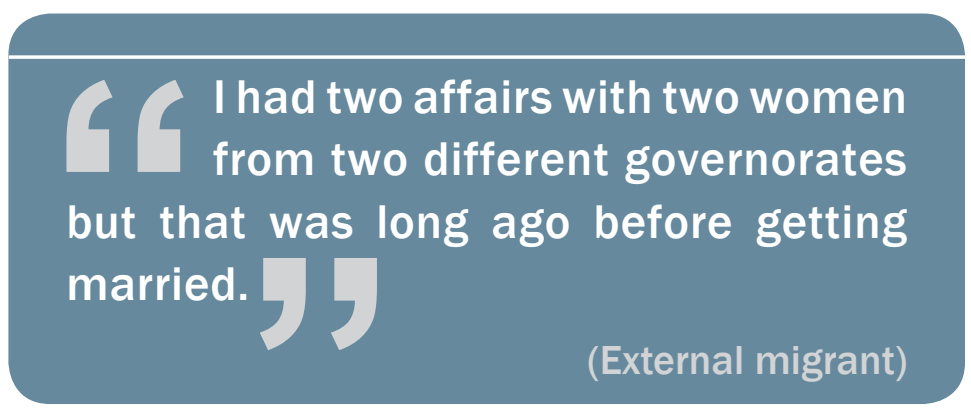

\section{Condom use among external migrants}

Most of the interviewed migrant workers had never used a condom before and some did not even know what a condom was. Only five men reported previous use of a condom with their wives: four 
of them used it as a contraceptive method, while one used it when his wife had her menstrual period. Most migrant workers believed that there was no need to use a condom with one's own wife and that condom use decreased sexual pleasure. They said that they would rather wait until menstrual bleeding stops and not use a condom.

However, condom use varied among men who had extramarital affairs. The man who had sex with sex workers said he always used a condom, while the one who had long-term sexual partners said that he used condoms with his first two partners but not with his current partner because he was certain that she was faithful to him. The third man reported that he usually used a condom, especially if he was suspicious of his partner, whereas the fourth man who had a one-time affair said he used a condom while having this affair. On the other hand, the two men who had premarital sex did not use a condom, while one of the participants who said that he did not have any affairs stated that he would definitely use a condom if he ever had an affair.

\section{Drug use among external migrants}

Several participants explained that external migrants were not interested in drugs, because they worked very hard to earn money and did not want to waste their money on drugs. Thus, none of the migrant workers indicated that they were using injecting drugs or knew someone who injected drugs. Also, most of them did not use other drugs or alcohol. Two men reported using hashish occasionally, two consumed alcohol occasionally, while one man used alcohol weekly and hashish daily. According to the migrant workers "pills" were generally hard to obtain, but alcohol specifically beer, was widely available and used by some of the people they knew. One man who works 12 hours a day said that his fellow workers used Tramadol in order to stay focused late at night.

\section{External migrants and HIV knowledge}

Interviewed external migrants seemed aware that HIV could be transmitted through sex and blood (i.e., sharing needles or blood transfusions). However, they also had many misconceptions about HIV, including: no treatment is available for HIV; HIV patients are put in solitary confinement; women can acquire HIV while washing in a polluted water canal; HIV can be transmitted through sharing of clothes, kissing, skin-rubbing, and sweat-mixing with an HIV-positive individual; HIV is transmitted through sex only when sexual organs are wounded and bleeding, and some insects can transmit HIV.

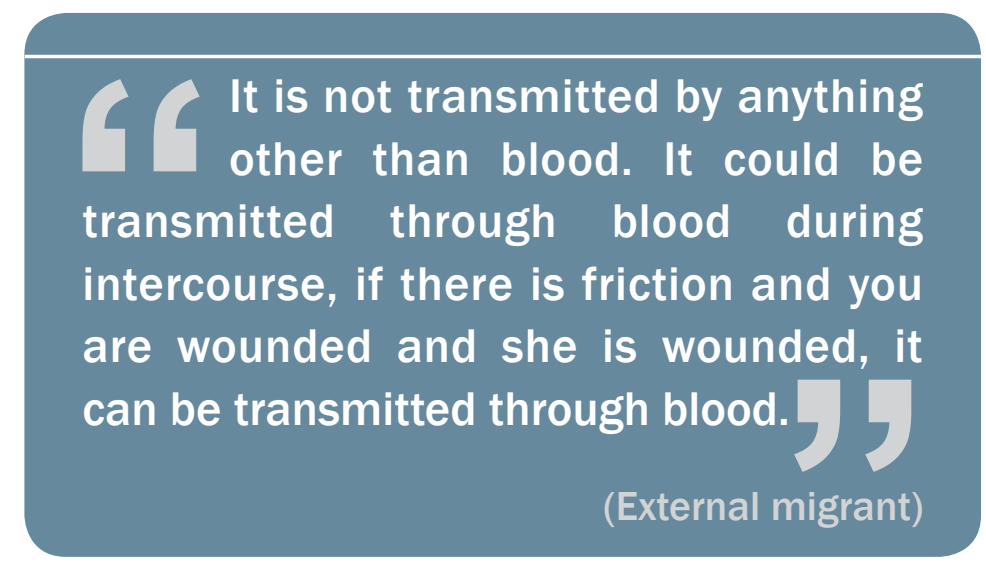


Furthermore, two men believed that because women have a higher sexual desire than men, they sometimes resort to having sex with animals, such as dogs, when they are not sexually satisfied. Then, they transmit HIV to men through sex. Two other men believed that women could transmit HIV to men, and not vice versa. They added that the period of time a woman has to wait before remarrying, according to Islam's religious teachings, is meant to cleanse the woman's body of any semen that might carry HIV to her second husband.

In terms of protection against HIV, most men mentioned abstinence from sex, being faithful to one's wife, ensuring proper testing of blood bags before transfusions, and avoiding sharing needles or shaving sticks with anyone. One man believed that although he had sex with several women, he protects himself from HIV by having one partner at a time. Despite most men indicating faithfulness to their wives, several of them believed that other external migrants were generally at risk for HIV because they were sexually frustrated and constantly struggling to remain faithful.

(External migrant)

However, many men indicated that risk of HIV depends on the person's religious beliefs and principles: if one is close to God, he will not practice any immoral behavior and thus, would not be at risk for HIV. They also seemed to agree that wives of external migrants could be at risk for two reasons: either

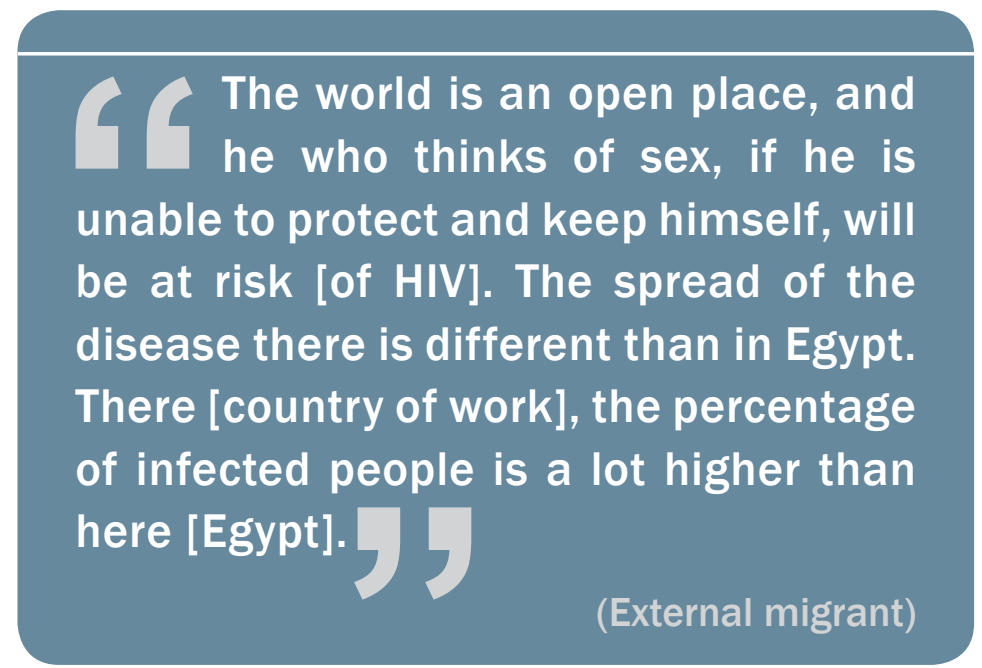
they have sex with other men while

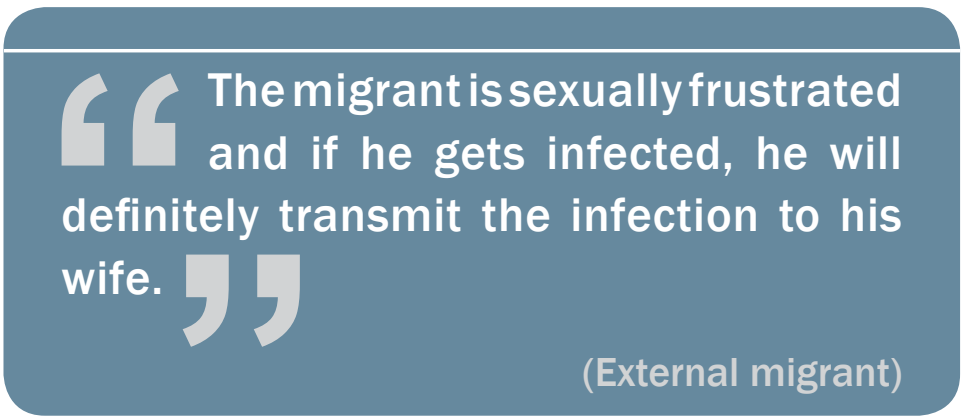
their husbands are away, or their husbands acquire HIV abroad and transmit it to them upon their return.

\section{External migrants and HIV testing}

None of the interviewed men reported ever being tested for HIV. It is noteworthy that HIV testing is mandatory for those who are applying to work in the Gulf States, but apparently some migrant workers were not informed about what they were being tested for. Furthermore, interviewed migrant workers did not know of any specific place that offers HIV testing. Some of them believed it would be available at any medical laboratory or health facility abroad. Others seemed familiar with the laboratories in Egypt such as El Borg, El Mokhtaber, and the central laboratories which 
offer HIV testing. Most men believed that HIV testing was not free in Egypt or in their host countries, however, three men said that it was free in their host country. One man believed that it would be very expensive to get tested in his host country.

\section{External migrants' suggestions to prevent HIV}

When migrant workers were asked to suggest protective measures against HIV for other external migrants and their wives, most men agreed that the best advice is to remain faithful and abstain from sex while abroad. They also thought that equally or more important advice is to strengthen their faith in God through prayer in order to help them abide by religious rules that prohibit adultery. Furthermore, they agreed that if a man insists on having extramarital sex, he should use a condom and get tested for HIV often. However, two men thought that a condom is not sufficient to protect oneself from HIV. Some suggested that the Egyptian Government should mandate HIV testing for external migrants before re-entering Egypt. A few external migrants said they would advise other external migrants to focus on work and remember their motive for living abroad, namely to financially support their loved ones. One man said he would advise other men not to travel if they are incapable of remaining faithful to their wives.

When asked about suitable means for reaching external migrants, many suggested social media as a good venue to raise awareness. They pointed out that posting on Facebook or creating a page where people can post anonymously and ask questions would be effective for many young men who are particularly vulnerable and are more likely to engage in risky behavior. Additionally, several participants believed that TV spots would be useful, particularly during football games, popular soap operas, and other television shows. Similarly, they suggested having a doctor or a person living with HIV speak on a popular show, or present an HIV case in a soap opera or a movie. However, one man noted that external migrants do not always have access to Egyptian television channels while abroad. Moreover, several participants believed that distributing brochures at airports before departure would efficiently target external migrants. Finally, several participants proposed having awareness-raising meetings at agencies that issued travel documents (e.g., passports and military service certificates) and at laboratories where men get their mandatory testing.

\section{Internal migrant workers}

We interviewed 20 male internal migrant workers who had been working and living outside their governorates for a period of not less than six months. They were aged 18-40 years and living in the slums of Cairo (five men) and Alexandria (five men) and in one tourist attractions (10 men). The majority of those in Cairo and Alexandria were illiterate or did not complete their elementary education and were mainly from Upper Egypt. They mostly worked in temporary jobs as construction workers or vendors in supermarkets. Internal migrants in the tourist attractions mostly had university degrees or secondary education. They all worked in the field of tourism, hotels, and related businesses such as sports or selling gifts. 


\section{Working outside their governorates}

Internal migrants in Cairo and Alexandria usually come from the same governorate and sometimes even the same village. They tend to form a closed community and keep their traditions and rural habits as if they were living in their own village. They usually work together and live together in one apartment (between 5-8 people) and split the rent and sometimes split the purchase of meat and cooking. They know each other and support each other in difficult circumstances such as illness or financial need. They are committed to their mission of working to earn money to support their families. They do not mingle much with the locals except at work. Most of them work for three months and have a vacation for one week to one month while the rest go back to their villages only for feast holidays or for the harvest season to work.

On the other hand, the internal migrants in the tourist attractions live in an open society; they mingle with others and do not necessarily abide by traditions and customs, but adopt those of the new society with all its temptations. The fact that they came from different communities made them more daring, as news about their extramarital relations would not reach their wives. Several of them made new friends and acquaintances from outside work, had relationships with women, and experimented with drugs. However, there are a few who still abide by conservative traditions which keep them away from risky practices, while others engaged in some risky behaviors for a while then stopped. They have a vacation ranging from three to 10 days everyone to one and a half months which they spend at home with their families.

\section{Internal migrants' marital relationship}

The majority of internal migrants in Cairo and Alexandria said that their relationship with their wives did not change, but that being apart increased the longing. Their wives appreciate their suffering and thus they try as much as possible to please them during their vacations. They can understand if their wife is not feeling well and does not want to have sex and hence they do not resort to violence with them. The sample that is working in tourist attractions believed that being apart is a great advantage as it increases longing. Most problems with their wives are solved over the phone so they can have a good time during their home leave. They do not tell their wives about their relationships with other women or their drug use. They mentioned that their relationships with foreign women were more satisfying because they learn new sex positions and things which they never practice with their wives who are "very traditional."

\section{Internal migrants' sexual relations}

Internal migrants in Cairo and Alexandria reported that they overcame their sexual desire while away from their wives through masturbation or doing nothing. They try not to stay for long periods away from their wives although several of them indicated that they and their wives have gotten used to this life and accept the situation. Communication between them and their wives about 
sexual needs is largely indirect as revealed by the following quote by one of the participants, "When my wife calls and says, you have been away for a long time or says the kids are asking about you, I realize she needs me and I go back quickly"

Internal migrants in Cairo and Alexandria said that they knew men who engage in sexual relations with women other than their wives and that they were tempted but refused for religious and financial reasons. One of them said, "It is very easy.... You pay 100-300 pounds to a pimp and he will take you to these women. Instead, I can pay 20 pounds transportation to the village to my wife and not commit a sin."

On the other hand, interviewed internal migrants in tourist attractions were less likely to experience problems of sexual frustration as according to them they can easily have sex with foreign women. One of them said, "Those things [having sex] are very easy and abundant; if you look at a foreign woman she offers you to sleep with her." Moreover, a few internal migrants in tourist attractions said they were paid to have sex with foreign women who were usually older than themselves. Some end up marrying foreign women who come for extended periods of time in which case the woman pays all the costs.

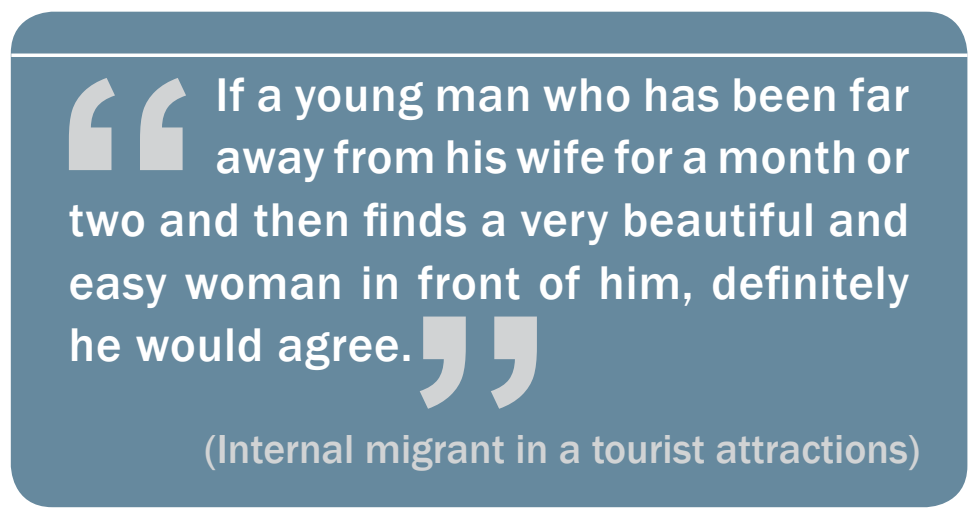

\section{Drug use among internal migrants}

Internal migrants in Cairo and Alexandria did not report use of alcohol or drugs except at weddings where alcohol and hashish are distributed free as a token of welcome to the guests. Participants who worked in the tourist attractions rarely used alcohol but were more likely to use Tramadol or Tamil because they believed that they prolonged the duration of sexual intercourse.

\section{Condom use among internal migrants}

Respondents from Cairo and Alexandria showed a severe lack of information about condoms with half of them reporting that they had never heard of them. Among those who had heard of condoms, the majority did not know the link between condom use and protection against HIV. The very few who reported ever using condoms said they did so either to prevent pregnancy or to have intercourse during their wife's menstrual period. When asked about their response if their wife asked them to use a condom, eight rejected while two added that they were entitled to know why and if the cause for that request was medical they would use it.

On the other hand, participants who worked in the tourist attractions all knew about condoms and reported using them with foreign female sex partners. However, it is usually the woman 
who demands the use of a condom and the one who supplies it. A few men added that they sometimes practice sex without condoms and that they understand the risks of this behavior. One of them used the condom with his wife as a family planning method. When asked about their response if their wife asked them to use a condom, they all rejected the idea.

\section{Internal migrants and HIV knowledge}

Migrant workers in Cairo and Alexandria have many misconceptions about HIV. Some believed that HIV can be transmitted via touching, kissing, and sharing of personal utensils, as well as through sneezing, spray and being with an AIDS patient in a closed place. Only three mentioned through sexual relations, one stated homosexual relations, and one stated sharing a syringe with an infected person. Several of them were under the impression that HIV/AIDS does not exist in Egypt but only in Western countries "where men and women live together before marriage and where women have multiple sex partners." Thus those workers did not see themselves as vulnerable to HIV/AIDS as long as they were committed to their religion and morals and did not have extramarital affairs.

Participants in the tourist attractions were generally better informed about HIV with many of them indicating that it was transmitted through sex and blood and that it destroys the immune system. They saw themselves and other migrants working in tourist attractions as vulnerable to HIV infection along with their wives and children through transmission. Several of them expressed regret for working in tourism and getting involved in those risky practices and wished they could find work in Cairo or their governorates.

The majority of the internal migrants in Cairo, Alexandria, and the tourist attractions did not know where to go for HIV testing. In general they believed it was better to be tested in private laboratories and hospitals, because they do not trust government health units and hospitals. A few respondents in the tourist attractions stated that they wanted to know where to go for confidential, anonymous testing but were afraid to ask.

\section{Internal migrants' suggestions to prevent HIV}

Suggestions of internal migrants in Cairo and Alexandria for the prevention of HIV/AIDS were to avoid extramarital affairs and to shorten the periods of separation from one's wife. However, they did not suggest condom use due to their limited knowledge of its preventive role. As to the best platforms for delivering information, TV occupied the first place, then came seminars for workers who do not have fixed jobs but change jobs frequently, as well as in factories and companies, in addition to mosques and churches.

Those in the tourist attractions suggested reduction of extramarital affairs, regular HIV testing for those working in tourism, and consistent condom use. In addition to the platforms listed by Cairo and Alexandria workers, they added the radio for taxi drivers working with foreigners, YouTube, and distributing leaflets and booklets at the workplace. 



\section{CONCLUSION}

The current study revealed that women and men are vulnerable to HIV infection as a result of several inter-related factors. However, due to inequitable societal gender norms, women are disproportionately more vulnerable to HIV infection even if they themselves are not practicing risky behaviors. These women who are not engaging in risky behaviors themselves can still be vulnerable to HIV via the risky behaviors of their husbands. The current study revealed that PWID share needles, have unprotected sex and forced sex, exchange sex for money, all under the influence of drugs. MSM practice unprotected sex with multiple partners and sometimes of both sexes while some migrant workers practice risky behaviors. However, none of the men who practice risky behaviors reported using a condom with his wife either because he does not want to raise her suspicion or he does not perceive her as a source of infection, i.e., he only thinks about his safety. The study also revealed that external migrant workers and internal migrant workers in tourist attractions are engaging in multiple sexual relations which are mostly unprotected. Wives were almost all unaware of husbands' risky behavior and those who knew were unable to discuss the issue with their husbands for fear of violence. Those who tried to discuss the issue of risky behaviors or tried to protect themselves by refusing to have sex, were subjected to both physical and sexual violence which they preferred to tolerate rather than destroy their homes. Vulnerability of married women due to husbands' risky behavior is further aggravated by the socio-cultural, economic, legal and programmatic factors that undermine women's ability to protect themselves against infection. Following is an overview of these interacting factors that increase women vulnerability to HIV:

\section{Economic}

Economic hardship in Egypt forces many men to migrate (both internally and externally) which exposes those men to new lifestyles and potential risks. Also, financial dependence of women on their husbands leads those women to tolerate their husbands' violence or risky behavior as those wives have no other means to support themselves or their children if they get divorced.

\section{Socio-cultural}

Women are socialized to be submissive and weak and to accept husbands' violence or risky behavior as a fact of life. Likewise, norms and expectations of masculinity increase men's risktaking behaviors, such as using drugs and having sex with multiple partners. Married women who experience violence or who are suspicious of husbands' risky behaviors are often hesitant to question such behavior, negotiate condom use, or seek outside support. The HIV vulnerability of 
women is further compounded by the misunderstanding of religious teachings whereby women are made to believe that a husband has the right to beat his wife and to have sex with her against her will. Additionally, the prevalent "culture of silence" around issues of sexuality and women's restricted mobility limit women's access to HIV information and services.

\section{Programmatic}

The vertical nature of MOHP services (FP, MCH, and HIV) does not allow women seeking routine health services for themselves or their children to receive information on HIV. Moreover, harmreduction programs that target key populations (e.g., MSM and PWID) and promote safe sex and safe injection do not target other vulnerable groups such as migrant workers. Additionally, those programs do not target wives of key populations as reaching spouses of key populations would inevitably breach confidentiality regarding their husbands' high risk behaviors.

\section{Legal}

Ineffective enforcement of laws governing minimum age of marriage or laws protecting women exposed to intimate partner violence may further exacerbate women's vulnerability to HIV. Some of the current laws may also increase men's (and consequently women's) vulnerability to HIV, where the act of prostitution is criminalized for the provider of the service but not the clients.

\section{Stigma and discrimination}

HIV-related stigma has a particularly heavy impact on women as HIV/AIDS is perceived as a disease of people who practice promiscuous behavior causing both men and women to avoid HIV testing or seeking care in order to avoid being stigmatized. Key populations, such as MSM and PWID, and vulnerable populations such as women and migrant workers, are hesitant to seek services for fear of the discrimination and stigma society places on the disease and those who are infected with it. Also, the fact that drug use and homosexuality are highly stigmatized behaviors makes it hard for key populations to disclose those behaviors even to their wives and hence they are unable to take necessary precautions to protect their wives. Concurrently, the stigma linked to condom use and the negative attitudes husbands have toward it reduces the likelihood of its use and renders both husbands and wives vulnerable to infection. 


\section{RECOMMENDATIONS}

Addressing women's vulnerability to HIV requires multi-sectoral interventions that involve various stakeholders along with targeted interventions that specifically target key populations.

\section{Targeted interventions for MSM and PWID}

For low-prevalence settings like Egypt, the focus of HIV prevention should be on interventions that specifically target key populations such as drop-in centers, outreach by peer workers at hotspots where MSM and PWID congregate, peer education, distribution of free condoms and sterile syringes, along with harm reduction counseling. To maximize the benefits of those programs to women, those men should be educated on how to communicate their risky behavior to their wives and should be encouraged to use condoms with their wives and other sex partners. Convincing key populations to bring their wives/partners to harm-reduction sites requires ue of innovative approaches such as underscoring the value of HIV testing for protection of their children.

\section{Reaching out to migrant workers}

Targeted interventions should be directed to internal and external migrants who form a large percentage of the Egyptian population. There is an urgent need to raise awareness among internal and external migrants about HIV and eduating them about safe sex. This could be achieved through use of social media e.g. posting on Facebook or creating a page where migrants could post anonymously and ask questions. Additionally, migrants could be efficiently reached by distributing brochures at airports before their departure and by organizing awareness-raising meetings at agencies that issue travel documents and by creating a cadre of peer educators who can provide psychological support and HIV counseling.

\section{Integration of reproductive health and HIV services}

HIV counseling should be integrated into all RH services, including $\mathrm{MCH}$, FP and premarital care services. Provider-initiated HIV counseling and testing should be offered to pregnant women seeking antenatal care, especially those at higher risk. A series of culturally sensitive questions might be helpful in identifying those women. In fact, operations research is needed to test feasibility of implementing this strategy. 


\section{Combating stigma and discrimination}

Efforts are needed to reduce stigma against PLHIV as well as stigma linked to condoms. Combating stigma and discrimination and raising public awareness of HIV would concurrently increase uptake of HIV testing and other preventive services including harm-reduction services among key populations.

\section{Raising public awareness of HIV}

The majority of HIV/AIDS programming is currently aimed at key populations and PLHIV, which leaves little opportunity for the general population to gain awareness. Efforts should focus on HIV/AIDS education, mass media campaigns to educate the public about modes of transmission and address prevalent misconceptions, in addition to social marketing of VCT services and condoms at a national scale.

\section{Law enforcement and legal reform}

Article 53 of the 2014 Egyptian Constitution commits the State to take necessary measures to eliminate all forms of discrimination and to ensure equality amomg all citizens.Loopholes in the current legal system should be addressed to protect married women against HIV. Issues like unequal punishment of men and women in prostitution and adultery crimes should be addressed. Women should be made aware of laws protecting them against violence and marital rape. Efforts should be made to educate police officers and district attorneys about the needs of women who are exposed to gender-based violence.

\section{Women's empowerment and promoting gender equality}

It is important to find ways to empower women by increasing their access to education and employment opportunities and by implementing policies and programs that eliminate gender inequaly. Adddressing inequitable gender norms must be part of all HIV programs. Women in abusive relationships should be offered shelter as well as medico-legal services. Additionally, programs that empower women by providing vocational training, life skills, financial skills, and access to work should be scaled up. Misunderstanding of religious teachings yields women submissive to abusive marital relationships and hence should be addressed. 




\section{REFERENCES}

Abdel-Tawab N. and D. Oraby . 2015. Supporting reproductive health of youth in Egypt: A call for enhancing partnerships (Arabic). Cairo: Population Council.

Aidaoui, M., S. Bouzbid, and M. Laouar. 2008. "Seroprevalence of HIV infection in pregnant women in the Annaba Region (Algeria)," Rev Epidemiol Santé Publique 56: 261-66.

Bruce, J. 2003. Overview and Reflections of Child Marriage and Adolescent Policy. Washington, DC, USA: ICRW.

Central Agency for Public Mobilisation and Statistics (CAPMAS), Minnesota Population Center. 2011. Egypt General Census for Population, Housing, and Establishments 2006 from the Integrated Public Use Microdata Series, International: Version 6.1 [Machine-readable database]. Minneapolis: University of Minnesota.

El-Zanaty, F. and A. Way. 2015. Egypt Demographic and Health Survey 2014. Cairo: Ministry of Health and Population, El-Zanaty and Associates, and Macro International.

Family Health International and Ministry of Health Egypt (FHI/MoH). 2010. HIV/AIDS Biological \& Behavioral Surveillance Survey: Round Two Summary Report. Cairo: $\mathrm{FHI} / \mathrm{MoH}$.

Handoussa, H. 2010. Situation Analysis: Key Development Challenges Facing Egypt. New York: United Nations Development Program.

Hermez, J.; J. Petrak, M. Karkouri, and G. Riedner. 2010. “A review of HIV testing and counseling policies and practices in the Eastern Mediterranean Region," AIDS 24: S25-S32.

Jenkins, C., and D. A. Robalino. 2003. "HIV in the Middle East and North Africa: The Cost of Inaction." Orientations in Development Series. Washington, DC:World Bank.

Khattab, H. and M. El-Geneidy. 2014. “Living with AIDS: Suffering and Courage." Cairo: Egyptian Society for Population Studies and Reproductive Health (ESPSRH).

Khattab, H. et al. 2007. "All Alone: The Stories of Egyptian Women Living with HIV, Stigma and Isolation." Cairo: ESPSRH.

Khattab, H. et al. 2010. "The Agony of AIDS: A Qualitative Study of the Experience of AIDS in Egypt." Cairo: ESPSRH.

Michalopoulos, L.M., A. Aifah, and N. El-Bassel. 2016. “A systematic review of HIV risk behaviors and trauma among forced and unforced migrant populations from low and middle-income countries: State of the literature and future directions." AIDS Behav. 20(2): 243-261. 
Ministry of Economic Development and the United Nations Development Program (UNDP). 2010. Egypt's Progress Towards Achieving The Millennium Development Goals. Cairo: Ministry of Economic Development.

Ministry of Health and Population (Egypt), El-Zanaty and Associates (Egypt), and ICF International. 2015. Egypt Demographic and Health Survey 2014. Cairo and Rockville, MD: Ministry of Health and Population and ICF International

Nabhan, A.F., A. El-Sara, M. Zein, and N. Usama. 2013. “Women's Vulnerabilities to HIV in Egypt: An Evidence Profile." Cairo: Ain Shams University.

National AIDS Program (NAP). 2013. A Guideline for Clinical Management of HIV/AIDS and ARVs. Cairo: Ministry of Health and Population.

National AIDS Program (NAP). 2014. Global AIDS Response Progress Report 2014. Cairo: Ministry of Health and Population.

National AIDS Program (NAP). 2015. National HIV Programme Situation and Gap Analysis. Cairo: Ministry of Health and Population.

Newman S, Sarin P, Kumarasamy N, Amalraj E, Rogers M, Madhivanan P, Flanigan T, Cu-Uvin S, McGarvey S, Mayer K, Solomon S.2000: Marriage, monogamy and HIV: a profile of HIVinfected women in south India. Int J STD AIDS. 2000 Apr;11(4):250-3.

Oraby, D. and N. Abdel-Tawab. 2014. Sexual and Reproductive Health of Women Living with HIV in Egypt: Unmet Needs and Unfulfilled Dreams. Cairo: Population Council.

Population Council 2007. Reproductive Health and Rights of HIV-Positive Individuals: Establishing a Global Program. New York: Population Council.

Pulerwitz, J., A. Michaelis, R. Verna, and E. Weiss. 2010. “Addressing gender dynamics and engaging men in HIV programs: Lessons learned from Horizons research," Public Health Reports, vol. 125: 282-292.

Puria, M. and J. Cleland. 2006. "Sexual behavior and perceived risk of HIV/AIDS among young migrant factory workers in Nepal," Journal of Adolescent Health 38 (3): 237-246.

Razzaghi, E. M., A. R. Movaghar, T. C. Green, and K. Khoshnood. 2006. "Profiles of risk: A qualitative study of injecting drug users in Tehran, Iran." Harm Reduct J 3: 12.

Saggurti, N., B. Mahapatra , S, Sabarwal, S. Ghosh, and A. Johri. 2012. "Male out-migration: A factor for the spread of HIV infection among married men and women in rural India." PLoS ONE 7(9): e43222. doi:10.1371/journal.pone.0043222 
Sieverding M. and A.Ragab . 2015." Marriage and Family Formation Trends among Youth in Egypt" In: Rania Roushdy and Maia Sieverding (eds) Panel Survey of Young People in Egypt (SYPE) 2014. Generating Evidence for policy, programs and research. Cairo: Population Council.

Silverman, J.G., M. R. Decker, N. Saggurti, D. Balaiah, and A. Raj. 2008. “Intimate partner violence and HIV infection among married Indian women," JAMA 300(6): 703-710.

Solomon, S. et al. 2010. "The impact of HIV and high-risk behaviours on the wives of married men who have sex with men and injection drug users: Implications for HIV prevention," Journal of the International AIDS Society 13(Suppl. 2): S7.

Speizer, I.S. and E. Pearson. 2011. "Association between early marriage and intimate partner violence in India: A focus on youth from Bihar and Rajasthan," Journal of Interpersonal Violence 26(10): 1963-1981.

UNAIDS. 2011. “Middle East and North Africa: Regional Report on AIDS 2011.” Geneva: UNAIDS.

UNAIDS/MENA. 2012. "Standing up Speaking Out-Women and HIV in the Middle East and North Africa." Issue Brief. Cairo: UNAIDS/MENA

Vivian, F. et al. 2003. "When HIV-prevention messages and gender norms clash: The Impact of domestic violence on women's HIV risk in slums of Chennai, India," AIDS and Behavior 7(3): 263-272.

World Health Organization (WHO) 2012. 16 ideas for addressing violence against women in the context of HIV epidemic: a programming tool. Geneva: World Health Organization.

2013. Global and regional estimates of violence against women: Prevalence and health effects of intimate partner violence and non-partner sexual violence. Geneva: World Health Organization. 

Population Council/Egypt

59 Misr-Helwan Agricultural Road, Maadi

PO Box 168, Maadi

Cairo, Egypt

11431

Tel. +20 225255968

Fax: +20 225255962

www.popcouncil.org 